\title{
Exposure to High-Altitude Environment is Associated with Drug Transporters Change: miR-873-5p-Mediated Alteration of Function and Expression Levels of Drug Transporters under Hypoxia
}

Yabin Duan $^{\mathrm{a}, \mathrm{b}_{\dagger}}$, Xue Bai ${ }^{\mathrm{b}} \uparrow$, Jianxin Yang ${ }^{\mathrm{b}}$, Yang Zhou ${ }^{\mathrm{d}}$, Wenqi Gu ${ }^{\mathrm{d}}$, Guiqin Liu ${ }^{\mathrm{b}}$, Qian Wang ${ }^{\mathrm{d}}$, Junbo Zhu ${ }^{\mathrm{b}}$, Linli La, Xiangyang $\mathrm{Li}^{\mathrm{c}, \mathrm{d}^{*}}$

${ }^{a}$ Department of Clinical Pharmacy, Qinghai University Affiliated Hospital, Xining, 810001, China

${ }^{b}$ Research Center for High Altitude Medicine, Qinghai University Medical College, Xining, 810001,

China

${ }^{c}$ State Key Laboratory of Plateau Ecology and Agriculture, Qinghai University, Xining 810016, China

${ }^{d}$ Medical College, Qinghai University, Xining 810001, China

"Corresponding author: Li Xiangyang, State Key Laboratory of Plateau Ecology and Agriculture, Qinghai University, No. 256 Ningda Road, Xining City, 810016, China, Phone 86-09715362082; Fax: 86-09715362383; E-mail: qhmclxy@ 163.com.

$\dagger$ These authors contributed equally to this work 


\section{Running Title: miR-873-mediated alteration of drug transporters in hypoxia}

Total number of manuscript pages: 48

Total word count of the Abstract: 247

Total word count of the Introduction: 744

Total word count of the Discussion: 1748

number of tables: 4

number of figures: 9

number of references: 65

number of words: 10576

\section{ABBREVIATIONS:}

miRNA, microRNA; MDR1, multidrug resistance protein 1; MRP2, multidrug resistance-associated protein 2; BCRP, breast cancer resistance protein; PEPT1, peptide transport 1; OATP2B1, organic anion-transporting polypeptides 2B1; PXR, pregnane $\mathrm{X}$ receptor. 


\section{ABSTRACT}

Hypoxia is the main characteristic of a high-altitude environment, affecting drug metabolism. However, so far, the mechanism of miRNA involved in the regulation of drug metabolism and transporters under high-altitude hypoxia is still unclear. This study aims to investigate the functions and expression levels of multidrug resistance protein 1 (MDR1), multidrug resistance-associated protein 2 (MRP2), breast cancer resistance protein (BCRP), peptide transport 1 (PEPT1), and organic anion-transporting polypeptides 2B1 (OATP2B1) in rats and Caco-2 cells after exposure to high-altitude hypoxia. The protein and mRNA expression of MDR1, MRP2, BCRP, PEPT1, and OATP2B1 were determined by Western blot and qPCR. The functions of MDR1, MRP2, BCRP, PEPT1, and OATP2B1 were evaluated by determining the effective intestinal permeability and absorption rate constants of their specific substrates in rats under high-altitude hypoxia, and uptake and transport studies were performed on Caco- 2 cells. To screen the miRNA associated with hypoxia, Caco-2 cells were examined by high throughput sequencing. We observed that the miR-873-5p was significantly decreased under hypoxia and might target MDR1 and pregnane $X$ receptor (PXR). To clarify whether miR-873-5p regulates MDR1 and pregnane $X$ receptor $(P X R)$ under hypoxia, Caco-2 cells were transfected with mimics or inhibitors of miR-873-5p and negative control (NC). The function and expression of drug transporters were found to be significantly increased in rats and Caco-2 cells under hypoxia. We found that miR-873-5p regulated MDR1 and PXR expression. Herein, it is shown that miRNA may affect 
the expression of drug transporter and nuclear receptor under hypoxia.

\section{SIGNIFICANCE STATEMENT}

This study explores if alterations to the microRNAs, induced by high-altitude hypoxia, can be translated to altered drug transporters. Among miRNAs, which show a significant change in a hypoxic environment, miR-873-5p can act on the MDR1 gene; however, there are multiple miRNAs that can act on the PXR. We speculate that the miRNA-PXR-Drug transporter axis is important in the physiological disposition of drugs. The results of this study are anticipated to be helpful for rational pharmaceutical use in high-altitude environments.

Keywords: High-altitude Hypoxia, Drug Transporters, miR-873-5p, Function, Expression. 


\section{Introduction}

Since ancient times, it has been a long-known fact that human beings can experience dyspnea caused by hypoxia in high-altitude areas. The first clear description of mountain sickness experienced by lowland natives at high altitudes was written by the priest Jose de Acosta in 1590 (Gilbert et al., 1983). The prominent feature of a high-altitude environment is solar radiation, decreased ambient oxygen tension, extreme diurnal range of temperature, arid climate, poor soil quality, etc., but the most striking feature is hypoxia (Eide et al., 2012). With the increase in altitude, the atmospheric pressure and partial pressure of oxygen decreased. The partial pressure inhaled, alveolar oxygen, and alveolar oxygen diffusion into the blood had corresponding changes due to the decrease in the partial pressure of oxygen in the atmosphere. In addition, studies found that the hypoxemia and tissue hypoxia, caused by arterial oxygen pressure and oxygen saturation decrease, become more intense as a result of altitude change (Simon et al., 2014).

The circulatory, nervous, and endocrine systems are adversely influenced by high-altitude hypoxia, which alters essential bodily functions, metabolism and cell structures and contributes to altitude sickness (Netzer et al., 2013). Altitude sickness is influenced by the speed of entering the hypoxic areas of the plateau, the length of stay, and the unique metabolism and status of individuals. Slow entry into high altitude elicits a compensatory response, and rapidly moving to higher altitudes causes tissue and cellular metabolic dysfunction and functional disorders. Additionally, acute hypoxia can directly cause altitude sickness, pulmonary edema and cerebral edema, whereas chronic hypoxia induces polycythemia and cardiovascular diseases (Mairbaurl et al., 1994; Imray 
et al., 2010).

Research on high-altitude hypoxia has focused on high-altitude disease prevention, nutrition, and high-altitude plateau adaptation (Rashid et al., 2013); recently, emphasis has been laid on high-altitude hypoxia and drug metabolism (Zhang et al., 2019). The drug absorption, distribution, metabolism, and excretion (ADME) are changed under hypoxic conditions, which alter the pharmacokinetics (Anjana et al., 2012). Cytochrome P450 enzymes and drug transporters play an important role in the physiological disposition of drugs, and the chemical and non-chemical factors affect the expression of the CYP450 family and transporters family gene at the transcriptional level (Qiao et al., 2019; Nivoix et al., 2008). There are many studies conducted on non-chemical factors, such as biophysical influences, pathological states, diseases, constitutional features, but it is also necessary to carry out more typical research on the effect of hypoxia on CYP450 and transporters. (Vesell et al., 1977; Jones et al., 1989).

Numerous studies have shown that the pharmacokinetics of lidocaine hydrochloride, sulfamethoxazole, lithium, acetazolamide, meperidine, and prednisolone significantly changed at high altitudes. (Zhang et al., 2016; Li et al., 2009; Li et al., 2012; Arancibia et al., 2003). Several previous studies have found increased expression of CYP3A6 and decreased expression of CYP1A1, 1A2, 2B4, 2C5, and 2C16 in rabbits after acute exposure to hypoxia (Fradette et al., 2007; Fradette et al., 2002; Kurdi et al., 1999; Fradette et al., 2004). In our previous study, we reported that CYP1, CYP2, CYP3, and NAT2 expressions significantly changed in rats at high altitudes. (Li et al., 2012; Li et al., 2014a; Li et al., 2014b). Drug transporters play a key role in the physiological disposition 
of drugs, which is also influenced by chemical and non-chemical factors. All these effects will change the effectiveness of drugs and further impact the clinical treatment. Jennifer $e t$ al. found that low-oxygen tumor environments induced the activity of MDR1, MRP1, and BCRP by activating and increasing the expression of these transporters in several cancer cell lines (Jennifer et al., 2017).

miRNAs are small endogenous RNAs that regulate gene expression. Research on the role of miRNA in drug metabolism is expanding because miRNAs are key regulators of gene expression (Lu et al., 2018). He et al. reviewed the effects of miRNA on the ADME of drugs, and summarized a hypothetical network that comprises 189 regulatory relationships between miRNA and their genes, and involves 120 miRNAs and 261 ADME genes, such as miR-148a-regulated PXR, miR-92a-regulated PEPT1, miR-7, miR-27a, miR-451-regulated MDR1, etc. (He et al., 2015).

However, to date, there are no reports that resolve the problem of changes in the activity and expression of drug transporters due to high-altitude hypoxia. In addition, the role of miRNA in regulating drug transporters under hypoxia is not clear. Consequently, we investigated the function and expression levels of MDR1, MRP2, BCRP, PEPT1, and OATP2B1 and their mechanism in the hypoxic environment at high altitudes.

\section{Materials and Methods}

Chemicals. Primary antibodies of $\beta$-Actin (1:500, mouse monoclonal, Abcam, ab8226), MDR1 (1:1000, rabbit monoclonal, Abcam, ab170904), MRP2 (1:1000, rabbit polyclonal, Sigma-Aldrich, M8316), BCRP (1:500, rabbit monoclonal, Abcam, ab207732), PEPT1 (1:500, rabbit polyclonal, Thermo Fisher, PA5-37010), and OATP2B1 (1:500, rabbit 
polyclonal, Novus, NBP-1-59811) were used for Western-blot test. RNAiso Plus and PrimeScript $^{\mathrm{TM}}$ RT Reagent were obtained from Takara Bio Inc. (Kyoto, Japan). The primers used for real-time PCR were synthesized by Shanghai Sangon Biotech Co., Ltd. (Shanghai, China). Rhodamine 123 (Lot: L630S74), Vincristine (Lot: LQCOS60), Prazosin (Lot: L780R01), Ubenimex (Lot: B3XEH-DO) and Glibenclamide (Lot: L910Q73) were purchased from J\&K Scientific Co., Ltd. (Beijing, China). Caco-2 cell line was obtained from the Chinese Academy of Sciences Cell Bank (Shanghai, China). Fetal bovine serum (FBS) was purchased from Biological Industries Co., Ltd. (Shanghai, China). LC/MS grade methanol, acetonitrile, and ultrapure water were purchased from Thermo Fisher Scientific (Shanghai, China). Lipofectamine 3000 Transfection Reagent (Lot: L3000015) was purchased from Invitrogen Biotech Co., Ltd. (California, USA).

Treatment of animals. A total of 250 male Sprague Dawley rats $(200 \pm 20 \mathrm{~g}$; Certificate No. 2018-001) of Specific Pathogen Free grade were provided by Xi'an Jiaotong University Medical College. Ten animals were housed per cage with separate rooms to ensure that each of them could be restrcted to a single space so as to avoid restraint stress. All rats were kept at room temperature at $23 \pm 2{ }^{\circ} \mathrm{C}$ with constant humidity of $55 \% \pm 5 \%$ under a $12 \mathrm{~h} \mathrm{light/dark}$ cycle for one week. The experimental procedures were conducted in accordance with the National Institutes of Health Guide for the Care and Use of Laboratory Animals, and the protocol was approved by the Animal Ethics Committee of The Qinghai University.

Two hundred and fifty male rats were randomly divided into MDR1, MRP2, BCRP, PEPT1, and OATP2B1 groups, and every group had fifty rats. MDR1, MRP2, BCRP, 
PEPT1, and OATP2B1 groups were further randomly divided into 5 subgroups, respectively, and every group had ten rats. The plain group (P, altitude: $390 \mathrm{~m}, \mathrm{PaO}_{2}$ : 20 $\mathrm{kPa}$ ) included 50 rats living in the city of Xi'an in Shanxi Province of northwest China. The acute moderate-altitude hypoxia group $\left(\mathrm{AMH}\right.$, altitude: $\left.2,800 \mathrm{~m}, \mathrm{PaO}_{2}: 15.1 \mathrm{kPa}\right)$ and the chronic moderate-altitude hypoxia group $\left(\mathrm{CMH}\right.$, altitude: $\left.2,800 \mathrm{~m}, \mathrm{PaO}_{2}: 15.1 \mathrm{kPa}\right)$ included 100 rats living in the city of Xi'an, but they received a 24-hour acute exposure and a 30-day chronic exposure to a middle-altitude area. The rats in these two groups were transported by bus to Gonghe County, Qinghai Province of northwest China, located at an altitude of 2,800 $\mathrm{m}$. The rats arrived in Gonghe County at 3:00 pm, and the tissues of each rat in the $\mathrm{AMH}$ group were collected at 3:00 pm, the following day after single-pass intestinal perfusion.Then, the tissues of rats in the $\mathrm{CMH}$ group were collected at 3:00 pm on the 31st day after single-pass intestinal perfusion. The acute high-altitude hypoxia group (AHH, altitude: 4,300 m, $\mathrm{PaO}_{2}: 12.4 \mathrm{kPa}$ ) and the chronic high-altitude hypoxia group $\left(\mathrm{CHH}\right.$, altitude: $\left.4,300 \mathrm{~m}, \mathrm{PaO}_{2}: 12.4 \mathrm{kPa}\right)$ consisted of 100 rats living in the city of Xi'an; however, the rats in the AHH group were acutely exposed to high altitudes for $24 \mathrm{~h}$, and the rats in the $\mathrm{CHH}$ group were chronically exposed to high altitudes for 30 days. The rats of $\mathrm{AHH}$ and $\mathrm{CHH}$ groups were transported to Maduo County by bus, which is in Qinghai Province of northwest China, to an altitude of $4,300 \mathrm{~m}$. Similar to the moderate-altitude experiment, the rats arrived in Maduo County at 9:00 pm, and the tissues of each rat in the AHH group were collected at 9:00 pm the following day and of rats in the $\mathrm{CHH}$ group at 9:00 pm on the 31st day after single-pass intestinal perfusion.

Sample collection of the P group was performed at Xi' an Jiaotong University Medical 
College, whereas the sample collection of the AMH and CMH groups was carried out at Gonghe County Hospital. Moreover, the sample collection of the $\mathrm{AHH}$ and $\mathrm{CHH}$ groups was performed at Maduo County Hospital. To determine the expression and function of drug transporters, all tissues were stored in liquid nitrogen and were transported to the Research Center for High Altitude Medicine of Qinghai University by bus.

The absorption of the specific substrates of MDR1, MRP2, BCRP, PEPT1 and OATP2B1 was measured in the rats' intestines by the intestinal perfusion method. The concentration of each substrate (MDR1: Rhodamine 123, MRP2: Vincristine, BCRP: prazosin, PEPT1: Ubenimex, OATP2B1: Glibenclamide) was determined by a high-performance liquid chromatography system (HPLC, Agilent 1200, California, USA).

Evaluation of the Functions of MDR1, MRP2, BCRP, PEPT1, and OATP2B1 in

Rats. The functions of MDR1, MRP2, BCRP, PEPT1, and OATP2B1 were evaluated by the single-pass intestinal perfusion method. Before experiments, rats were immediately anesthetized via enterocoelia injection with sodium pentobarbital $(50 \mathrm{mg} / \mathrm{kg})$. Following this, the rats were placed on a heated operating table to keep the body temperature at $37^{\circ} \mathrm{C}$. All rats were given laparotomy, and a 10-15 cm intestinal segment (duodenum, jejunum, and ileum) was isolated. Both ends of the intestinal segment were cannulated with plastic tubing. The intestinal segment was washed with sterile normal saline at $37^{\circ} \mathrm{C}$ to clear the content. Next, intestinal perfusion was performed with Krebs-Ringer solution that contained phenol red and substrates of MDR1, MRP2, BCRP, PEPT1, and OATP2B1 at $37^{\circ} \mathrm{C}$. The intestine was perfused for $30 \mathrm{~min}$ at a rate of $1 \mathrm{~mL} / \mathrm{min}$ to stabilize the state of 
rats and then perfused for $120 \mathrm{~min}$ at a rate of $0.2 \mathrm{~mL} / \mathrm{min}$ by a peristaltic pump (BT100-2J, Heibei, China). The Krebs-Ringer solution and the collection bottle were replaced every $15 \mathrm{~min}$. The intestine was cut off at both ends of the intubation, and the length and inner diameter of the intestine were measured. The substrates of MDR1, MRP2, BCRP, PEPT1, and OATP2B1 are shown in Table 1. The absorption rate constant $\left(\mathrm{K}_{\mathrm{a}}, \mathrm{s}^{-1}\right)$ and intestinal effective permeability $\left(\mathrm{P}_{\text {eff, }} \mathrm{cm} / \mathrm{s}\right)$ of the substrates were calculated according to the following formula (Chen et al., 2010; Li et al., 2017):

$$
C_{\text {out }(\text { corrected })}=\frac{C_{\text {out }} P R_{\text {in }}}{P R_{\text {out }}} \quad P_{\text {eff }}=\frac{Q \ln \left(C_{\text {in }} / C_{\text {out }(\text { corrected })}\right)}{2 \pi r l} \quad K_{a}=\left(1-\frac{\left.C_{\text {out }(\text { corrected })}\right)}{C_{\text {in }}}\right) Q / \pi r^{2} l
$$

Where $\mathrm{PR}_{\text {out }}$ and $\mathrm{PR}_{\text {in }}$ are the concentrations of outlet and inlet phenol red. $\mathrm{C}_{\text {out (corrected) }}$ is corrected outlet drug concentration, $\mathrm{C}_{\text {out }}$ is outlet drug concentration, and $\mathrm{C}_{\text {in }}$ is inlet drug concentration $(\mu \mathrm{g} / \mathrm{mL})$. Q is the flow rate in $\mathrm{mL} / \mathrm{min}(0.2 \mathrm{~mL} / \mathrm{min}), l$ is the length of the intestinal segment, and $r$ is the radius of the intestinal segment.

HPLC Analysis. The concentrations of rhodamine 123, vincristine, prazosin, ubenimex, and glibenclamide in the Krebs-Ringer solution were determined by HPLC. The Krebs-Ringer solution sample was processed with acetonitrile to denature the protein, and the mixture of acetonitrile and Krebs-Ringer solution was vortexed for $0.5 \mathrm{~min}$ and then centrifuged for $10 \mathrm{~min}$ at $16,000 \mathrm{~g}$ at $4^{\circ} \mathrm{C}$. A $10 \mu \mathrm{L}$ aliquot of the supernatant was injected into the HPLC system. $\mathrm{A} \mathrm{C}_{18}$ column (Agilent, Agilent Analytics, Inc., California, USA; $4.6 \times 250 \mathrm{~mm}$, inner diameter, $5 \mu \mathrm{m}$ ) was prepared in the HPLC system. Chromatographic conditions used were as follows:

Rhodamine 123: mobile phase: methanol-water $(70: 30, \mathrm{v} / \mathrm{v})$, column temperature: $40^{\circ} \mathrm{C}$, 
flow rate: $1.0 \mathrm{~mL} / \mathrm{min}$, detection wavelength: $229 \mathrm{~nm}$.

Vincristine: mobile phase: methanol-monopotassium phosphate solution (70:30, v/v), column temperature: $40^{\circ} \mathrm{C}$, flow rate: $1.0 \mathrm{~mL} / \mathrm{min}$, detection wavelength: $279 \mathrm{~nm}$.

Prazosin: mobile phase: methanol-monopotassium phosphate solution $(52: 48, \mathrm{v} / \mathrm{v})$, column temperature: $40^{\circ} \mathrm{C}$, flow rate: $1.0 \mathrm{~mL} / \mathrm{min}$, detection wavelength: $245 \mathrm{~nm}$.

Ubenimex: mobile phase: methanol-water $(63: 37, \mathrm{v} / \mathrm{v})$, column temperature: $40^{\circ} \mathrm{C}$, flow rate: $1.0 \mathrm{~mL} / \mathrm{min}$, detection wavelength: $254 \mathrm{~nm}$.

Glibenclamide: mobile phase: acetonitrile-water $\left(58: 42\right.$, v/v), column temperature: $30^{\circ} \mathrm{C}$, flow rate: $1.0 \mathrm{~mL} / \mathrm{min}$, detection wavelength: $230 \mathrm{~nm}$.

Cell Culture. Caco-2 cells (colon cancer cells) were used in this study. These cells were seeded on $6 \mathrm{~cm}$ culture plates and supplemented with $10 \%$ fetal bovine serum. Cultures were incubated at $37^{\circ} \mathrm{C}$ in a humidified $5 \% \mathrm{CO}_{2}$ incubator. Caco-2 cells were plated at a density of $2 \times 10^{5}$ cells per well into 6 -well plates or transwell plates. The protein and mRNA expressions of drug transporters were determined after the Caco- 2 cells were exposed to $2 \% \mathrm{O}_{2}$ for $24 \mathrm{~h}(2 \%-24 \mathrm{~h}), 10 \% \mathrm{O}_{2}$ for $24 \mathrm{~h}(10 \%-24 \mathrm{~h}), 5 \% \mathrm{O}_{2}$ for $24 \mathrm{~h}$ $(5 \%-24 \mathrm{~h}), 5 \% \mathrm{O}_{2}$ for $2 \mathrm{~h}(5 \%-2 \mathrm{~h}), 5 \% \mathrm{O}_{2}$ for $6 \mathrm{~h}(5 \%-6 \mathrm{~h}), 5 \% \mathrm{O}_{2}$ for $12 \mathrm{~h}(5 \%-12 \mathrm{~h}), 5 \%$

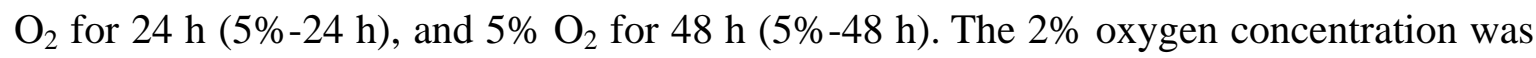
used for uptake and transport assays because the 2\%-24h group had the most significant effect on the expression of MDR1, MRP2, BCRP, PEPT1, and OATP2B1.

Uptake and Transport Study. The uptake and transport study was performed as described previously (Xiang et al., 2018). The Caco-2 cells were seeded at $1 \times 10^{5}$ 
cells $/ \mathrm{cm}^{2}$ in 6-well plates for the uptake study, and transwell polycarbonate inserts for transport study. Caco-2 cells were cultured for 14 days and 21 days for uptake and transport study, after seeding with the medium that was replaced every day.

For the uptake study, the culture medium was removed, and the cells were preincubated at $37^{\circ} \mathrm{C}$ for $20 \mathrm{~min}$ in $1 \mathrm{~mL}$ of Hank's balanced salt solution (HBSS) after exposure to hypoxia. The medium was replaced, and the cells were incubated with $2 \mathrm{~mL}$ of HBSS solution containing rhodamine 123 , vincristine, prazosin, ubenimex, and glibenclamide, for $30,60,90$, and $120 \mathrm{~min}$. The Caco-2 cells surface was quickly rinsed 3 times with ice-cold HBSS solution after incubation with substrates and were collected with a cell scraper, suspended in $1 \mathrm{~mL}$ of extraction solution and homogenized in an ultrasonicator. The concentration of substrates and protein was analyzed.

For the transport study, the reliability of the cell monolayer was assessed by measuring the transepithelial electrical resistance (TEER) with a Millicell-ERS-electrode (Millipore, Billerica, MA, U.S.A.). The Caco-2 cell monolayers were considered tight enough for the transport experiments when the TEER value was above $400 \Omega \cdot \mathrm{cm}^{2}$. The Caco- 2 cells were preincubated at $37^{\circ} \mathrm{C}$ for $20 \mathrm{~min}$ in $1 \mathrm{~mL}$ of $\mathrm{HBSS}$ after exposure to hypoxia. For influx direction, $0.5 \mathrm{~mL}$ substrates solution was added to the apical (AP) side, while 1.5 mL HBSS was added to the basolateral (BL) side. For efflux direction, $1.5 \mathrm{~mL}$ substrates solution was added to the BL side, and $0.5 \mathrm{~mL} \mathrm{HBSS}$ was added to the AP side. Then, $100 \mu \mathrm{L}$ sample was collected from receiver chambers every $30 \mathrm{~min}$ and immediately replaced with the same volume of fresh transport buffer until $120 \mathrm{~min}$. The concentration of the substrates was determined by UPLC-MS (Thermo Scientific Ultimate 3000 and 
Q-Exactive Focus MS, Sunnyvale, USA).

$$
P_{a p p}=\frac{(d C / d t)}{A C_{0}}
$$

Where $\mathrm{dC} / \mathrm{dt}(\mu \mathrm{mol} / \mathrm{s})$ is the rate at which the compound appears in the receiver chamber, $\mathrm{A}\left(\mathrm{cm}^{2}\right)$ is the surface area of the transwell polycarbonate membrane $\left(1.12 \mathrm{~cm}^{2}\right)$, and $\mathrm{C}_{0}(\mu \mathrm{mol} / \mathrm{L})$ is the initial concentration of drugs.

Sample Processing. The HBSS solution sample was processed with acetonitrile to denature the protein, and the mixture of acetonitrile, internal standard (IS), and HBSS solution was vortexed for $0.5 \mathrm{~min}$ and then centrifuged for $10 \mathrm{~min}$ at $11,400 \mathrm{~g}$ at $4^{\circ} \mathrm{C}$. An aliquot of the supernatant was analyzed using LC-MS (Thermo Scientific Ultimate 3000 and Q-Exactive Focus MS, Sunnyvale, USA).

Chromatographic conditions. An HPLC separation module (Thermo Scientific UltiMate 3000, Sunnyvale, USA) with a cooled autosampler and column oven was used in this assay. Thermo Hypersil GOLD $\mathrm{C}_{18} 50 \mathrm{~mm} \times 2.1 \mathrm{~mm}, 1.9 \mu \mathrm{m}$ column (Thermo Fisher, Sunnyvale, USA) was used for chromatographic separation. The gradient elution was performed as follows:

Ubenimex: flow rate: $0.3 \mathrm{~mL} / \mathrm{min}$, column temperature: $30^{\circ} \mathrm{C}$.

\begin{tabular}{ccc}
\hline Time $(\min )$ & methanol & 0.1\%formic acid-water \\
\hline 0 & 40 & 60 \\
4 & 40 & 60 \\
7 & 90 & 10 \\
\hline
\end{tabular}


Prazosin: flow rate: $0.3 \mathrm{~mL} / \mathrm{min}$, column temperature: $30^{\circ} \mathrm{C}$.

\begin{tabular}{ccc}
\hline Time $(\min )$ & methanol & 0.1\%formic acid-water \\
\hline 0 & 30 & 70 \\
2 & 30 & 70 \\
3 & 60 & 40 \\
10 & 60 & 40 \\
\hline
\end{tabular}

Vincristine: flow rate: $0.3 \mathrm{~mL} / \mathrm{min}$, column temperature: $30^{\circ} \mathrm{C}$.

\begin{tabular}{ccc}
\hline Time $(\min )$ & methanol & 0.1\% formic acid-water \\
\hline 0 & 30 & 70 \\
2 & 30 & 70 \\
3 & 70 & 30 \\
10 & 70 & 30 \\
\hline
\end{tabular}

Rhodamine 123: flow rate: $0.5 \mathrm{~mL} / \mathrm{min}$, column temperature: $40^{\circ} \mathrm{C}$.

\begin{tabular}{ccc}
\hline Time $(\min )$ & acetonitrile & 0.1\%formic acid-water \\
\hline 0 & 10 & 90 \\
1 & 10 & 90 \\
\hline
\end{tabular}




\begin{tabular}{lll}
\hline 1.1 & 95 & 5 \\
10 & 95 & 5 \\
\hline
\end{tabular}

Glibenclamide: flow rate: $0.5 \mathrm{~mL} / \mathrm{min}$, column temperature: $40^{\circ} \mathrm{C}$.

\begin{tabular}{ccc}
\hline Time $(\min )$ & acetonitrile & $0.1 \%$ formic acid-water \\
\hline 0 & 10 & 90 \\
1 & 10 & 90 \\
1.1 & 95 & 5 \\
10 & 95 & 5 \\
\hline
\end{tabular}

Mass spectrometry conditions. A high-resolution mass spectrum (Q-Exactive Focus MS, Sunnyvale, USA) was used to analyze samples in positive electrospray ionization mode, and data were collected and processed using Trace Finder 4.0 software. Source parameters adopted were as follows: sheath gas flow rate: 35 arb; aux gas flow rate: 10 arb; sweep gas flow rate: $1 \mathrm{arb}$; spray voltage: $3.5 \mathrm{kV}$; capillary temp: $260^{\circ} \mathrm{C}$; s-lens $\mathrm{RF}$ level: 50\%; aux gas heater temp: $300^{\circ} \mathrm{C}$. Rhodamine 123: $345.12337(\mathrm{~m} / \mathrm{z})$, Rhodamine 6G (Internal standard, IS): 443.23292 (m/z), Vincristine: $825.40692(\mathrm{~m} / \mathrm{z})$, Vinblastine (IS): 811.42766 (m/z), Prazosin: 384.16992 (m/z), Terazosin (IS): 387.19675 (m/z), Ubenimex: 309.18088 (m/z), Cilostazol (IS): 370.22375 (m/z), Glibenclamide: 494.15110 (m/z), and Glipizide (IS): 446.18565 (m/z).

Western Blot. Total protein samples were harvested from liver tissue and homogenated, and Caco-2 cells were lysed by ice-cold lysis buffer followed by content determination. 
The protein samples were separated by electrophoresis on 10\% SDS polyacrylamide gels, and then transferred to a polyvinylidene fluoride (PVDF) membrane. Tris-Buffered Saline Tween-20 (TBST) was used to block membranes with 5\% skimmed milk powder for $1.5 \mathrm{~h}$. The PVDF membranes were incubated with the primary antibodies of $\beta$-Actin (1:500, mouse monoclonal, Abcam, ab8226), MDR1 (1:1000, rabbit monoclonal, Abcam, ab170904), MRP2 (1:1000, rabbit polyclonal, Sigma-Aldrich, M8316), BCRP (1:500, rabbit monoclonal, Abcam, ab207732), PEPT1 (1:500, rabbit polyclonal, Thermo Fisher, PA5-37010), OATP2B1 (1:500, rabbit polyclonal, Novus, NBP-1-59811), respectively, at $4^{\circ} \mathrm{C}$ for overnight. The membranes were incubated with a 1:10000 dilution of the second antibody at $37^{\circ} \mathrm{C}$ for $1 \mathrm{~h}$. Specific protein bands were detected by the ECL system (Amersham imager 600, Boston, USA).

Quantitative Real-time Polymerase Chain Reaction. Liver tissue and Caco-2 cells were homogenized and total RNA was isolated using TRIzol reagent. The quality of the RNA solutions was assessed using a NanoDrop 2000c spectrophotometer (Thermo Fisher Scientific, USA). cDNA was synthesized according to the manufacturer's protocol. Relative mRNA expression was analyzed using the BIO-RAD CFX Connect Real-Time PCR System (Bio-Rad Laboratories, Inc., USA). For mature let-7f-5p, let-7g-5p, miR-522-3p, miR-873-5p, miR-148b-3p, and miR-148a-3p detection, reverse transcription was performed using poly(A)-tailed total RNA, a reverse transcription primer and reverse transcriptase. Products were amplified at $95^{\circ} \mathrm{C}$ for $5 \mathrm{~min}$, followed by 40 cycles at $95^{\circ} \mathrm{C}$ for $15 \mathrm{~s}, 60^{\circ} \mathrm{C}$ for $20 \mathrm{~s}$, and at $72^{\circ} \mathrm{C}$ for $40 \mathrm{~s}$. Fold induction values were calculated according to the equation $2^{-\Delta \Delta \mathrm{Ct}}$, where $\Delta \mathrm{Ct}$ represents the difference in cycle threshold 
numbers between the target gene and the control gene $\beta$-actin or U6, and $\Delta \Delta \mathrm{Ct}$ represents the relative change in the difference between the control and treatment groups. The primers are listed in Table 2-4. The sequence of primer was: reverse 5'-AGTGCAGGGTCCGAGGTATT-3' for all miRNAs. qPCR efficiency over all samples was calculated according to the Minimum Information for Publication of Quantitative Real-Time PCR Experiments (MIQE) guidelines.

RNA Sequencing for Caco-2 Cells. Briefly, total RNA was collected and lysed from Caco-2 cells with Trizol reagent after exposure to hypoxia or normoxia with Trizol reagent. The RNA quality was evaluated by a spectrophotometer (Thermo Fisher Scientific NanoDrop 2000c, USA). A library for Illumina (HiSeq 2500, San Diego, USA) platform was constructed consisting of miRNA enrichment, cDNA generation, and end repair to generate blunt ends, A-tailing, adaptor ligation, and PCR amplification. The differential miRNAs were considered up-regulated if fold change was $\geqslant 2$ and $P$-value was $\leqslant 0.05$, and down-regulated if fold change was $\leqslant 0.5$ and $P$-value was $\leqslant 0.05$.

miRNA Transfection. The Caco- 2 cells were plated at a density of $3 \times 10^{5}$ cells per well in 6-well plates and incubated at $37^{\circ} \mathrm{C}$ in a humidified $5 \% \mathrm{CO}_{2}$ incubator for $24 \mathrm{~h}$. The Caco-2 cells were transfected with $769 \mathrm{nmol} / \mathrm{L}$ mimics or inhibitors of miR-873-5p or negative control (NC) RNA as control using Lipofectamine 30EC00 and OPTI-MEM reduced serum medium according to the manufacturer's protocol. The miR-873-5p mimics and inhibitors were chemically synthesized by KeyGEN BioTECH.

Statistical Analysis. All numerical data were expressed as mean \pm SD. One-way 
analysis of variance (ANOVA) was used to analyze protein and mRNA expressions in rats and Caco-2 cells, followed by post hoc tests using Least Significant Difference (LSD). Independent-samples t-test was used for uptake and transport assay, and the difference of $P$ $<0.05$ was considered statistically significant. The rank-sum test was used for variance nonhomogeneity. All the statistical analyses were performed with the Statistical Package for the Social Sciences, version 13.0 (SPSS, Chicago, IL, USE).

\section{Results}

Expression of MDR1, MRP2, BCRP, PEPT1, and OATP2B1 in Rats. As shown in Figure 1a, the mRNA expression of MDR1 was significantly increased in the AMH and AHH groups, but decreased in the $\mathrm{CHH}$ group, compared to that in the $\mathrm{P}$ group. Compared with the $\mathrm{P}$ group, the mRNA expression of MRP2 was increased in the $\mathrm{AMH}$ and $\mathrm{CHH}$ groups, and mRNA expression of BCRP was increased in the AMH and AHH groups. Influx transporters also significantly changed in high-altitude hypoxia. The mRNA expression of PEPT1 was higher in the $\mathrm{AMH}, \mathrm{AHH}$ and $\mathrm{CHH}$ groups, and lower in the $\mathrm{CMH}$ group, compared with that in the P group. High-altitude hypoxia did not affect the mRNA expression of OATP2B1.

Rats received a 24-hour acute exposure and a 30-day chronic exposure to middle and high altitude levels. As shown in Figure 1b, changes in MDR1 protein expression were in conformity to the corresponding changes in mRNA expression. The protein expression of MDR1 was significantly decreased in high-altitude hypoxia. MRP2 protein expression was decreased in the AMH group, but increased in the $\mathrm{CHH}$ group. BCRP and PEPT1 protein 
expressions increased in high-altitude hypoxia, whereas the expression of OATP2B1 did not significantly change.

Functions of MDR1, MRP2, BCRP, PEPT1, and OATP2B1 in Rats. Figure 2 shows the absorption of rhodamine 123, vincristine, prazosin, ubenimex, and glibenclamide in the intestine expressed in the form of $\mathrm{P}_{\mathrm{eff}}$ and $\mathrm{K}_{\mathrm{a}}$. Comparable data were obtained from these two parameters. The experiments were performed using several specific substrates. Rhodamine 123 is a specific substrate for MDR1, vincristine for MRP2, prazosin for BCRP, ubenimex for PEPT1, and glibenclamide is specific for OATP2B1. Our data showed that the $\mathrm{P}_{\text {eff }}$ and $\mathrm{K}_{\mathrm{a}}$ form of rhodamine 123 decreased when the rats were exposed to acute high- altitude hypoxia. Compared to the $\mathrm{P}$ group, the $\mathrm{P}_{\mathrm{eff}}$ and $\mathrm{K}_{\mathrm{a}}$ form of vincristine in the AMH group significantly increased, but decreased in the $\mathrm{CMH}$ and $\mathrm{CHH}$ groups. The $\mathrm{P}_{\text {eff }}$ and $\mathrm{K}_{\mathrm{a}}$ form of prazosin, ubenimex, and glibenclamide increased when the rats were exposed to hypoxia, but the Peff and $\mathrm{Ka}$ form of prazosin in the $\mathrm{AHH}$ group significantly decreased. The above results suggested that the activity of MDR1, PEPT1, and OATP2B1 increased under hypoxic conditions, and BCRP decreased in CMH and CHH group; however, it increased in the AHH group. The activity of MRP2 was found to be reduced after exposure to acute moderate altitude hypoxia, but increased after exposure to chronic moderate and high-altitude hypoxia.

\section{Expression of MDR1, MRP2, BCRP, PEPT1, OATP2B1, and PXR in Caco-2 Cells.}

After Caco- 2 cells were treated with $5 \%$ oxygen concentration for $2,6,12,24$, and $48 \mathrm{~h}$ and $2 \%, 5 \%$, and $10 \%$ oxygen concentration for $24 \mathrm{~h}$, protein and mRNA expressions were assessed by Western blot and qPCR. As shown in Figure 3a, compared to the normoxia 
group, the mRNA expression of MDR1 in the 5\%-2h group was increased, BCRP increased in the $10 \%-24 \mathrm{~h}, 5 \%-2 \mathrm{~h}$, and $5 \%-6 \mathrm{~h}$ group, PEPT1 increased in the $2 \%-24 \mathrm{~h}$ group, but OATP2B1 decreased in the 5\%-6h group. There was no significant difference in the mRNA expression of MRP2 under hypoxia. In addition to the 5\%-2h group, the mRNA expression of PXR decreased in the 2\%-24h, 10\%-24h, 5\%-6h, 5\%-12h, 5\%-24h, and $5 \%-48 \mathrm{~h}$ group.

Figure $3 \mathrm{~b}$ shows the protein expression of MDR1, PEPT1, and OATP2B1 which significantly increased in the $2 \%-24 \mathrm{~h}, 10 \%-24 \mathrm{~h}, 5 \%-2 \mathrm{~h}, 5 \%-6 \mathrm{~h}, 5 \%-12 \mathrm{~h}, 5 \%-24 \mathrm{~h}$, and $5 \%-48 \mathrm{~h}$ group, compared to the normoxia group. BCRP increased in the $2 \%-24 \mathrm{~h}$, 10\%-24h, 5\%-6h, 5\%-12h, 5\%-24h, and 5\%-48h group. The protein expression of MRP2 and PXR significantly decreased in $2 \%-24 \mathrm{~h}, 10 \%-24 \mathrm{~h}, 5 \%-2 \mathrm{~h}, 5 \%-6 \mathrm{~h}, 5 \%-12 \mathrm{~h}, 5 \%-24 \mathrm{~h}$, and 5\%-48h group, compared to the normoxia group. We investigated the effect of time and oxygen concentration on the drug transporters, following $24 \mathrm{~h}$ treatment with $2 \%$ oxygen concentration, which had the greatest effect on MDR1, BCRP, PEPT1, and OATP2B1 protein expression. Therefore, $2 \%$ oxygen concentration was used for the subsequent uptake and transport experiment.

Effect of Hypoxia on the Uptake and Transport of Rhodamine 123, Vincristine, Prazosin, Ubenimex, and Glibenclamide. Similar to the in vivo experiment, the functions of MDR1, MRP2, BCRP ,PEPT1 and OATP2B1 were evaluated by analyzing the uptake and transport of rhodamine 123, vincristine, prazosin, ubenimex, and glibenclamide in vitro. As shown in Figure 4, compared to the normoxia group, the uptake of rhodamine 123 significantly increased at $90 \mathrm{~min}$, vincristine increased at 30, 60, and $90 \mathrm{~min}$, and 
ubenimex significantly increased at $120 \mathrm{~min}$. The uptake of glibenclamide decreased at 30 min, but increased at $120 \mathrm{~min}$. The uptake value did not significantly differ for prazosin. Figure 5 shows that the $\mathrm{P}_{\text {app }}$ of rhodamine 123 and ubenimex was significantly increased at 30, 60, 90, and 120 min under hypoxic conditions in the influx direction. The $\mathrm{P}_{\text {app }}$ of vincristine and glibenclamide significantly decreased at $30 \mathrm{~min}$ but increased at $60 \mathrm{~min}$ and 90 min under hypoxic conditions in the influx direction. The $\mathrm{P}_{\text {app }}$ of prazosin significantly decreased at 120 min under hypoxic conditions in the influx direction. Figure 6 shows that $\mathrm{P}_{\text {app }}$ of rhodamine 123 significantly increased at 30, 60, and $120 \mathrm{~min}$, but vincristine decreased at 90 min under hypoxic conditions in the efflux direction. The $\mathrm{P}_{\mathrm{app}}$ of prazosin and ubenimex significantly increased at 30,60, 90, and 120 min under hypoxic conditions in the efflux direction. The $\mathrm{P}_{\text {app }}$ of glibenclamide significantly increased at 30 and 60 min under hypoxic conditions in the efflux direction. The above-mentioned results suggest that the activity of efflux transporters MDR1 and BCRP increased, but the activity of MRP2 decreased under hypoxia. The activity of influx transporters PEPT1 was also found to be increased; however, the activity of OATP2B1 increased at 60 and $90 \mathrm{~min}$, and decreased at 30 min under hypoxia. Additionally, transport from AP to BL of rhodamin123 as well as transport from BL to AP of ubenimex was also increased by hypoxia, which suggested that the activity of influx transporters for rhodamin123 and efflux transporters for ubenimex also increased under hypoxia.

Effect of Hypoxia on miRNAs' Expression Profile in Caco-2 Cells. In a systematic approach to identifying miRNAs involved in hypoxia, we applied the well-established model of hypoxia treatment in Caco-2 cells. We then applied sequencing analysis to 
compare miRNA expression levels between hypoxia and normoxia and found that 27 miRNAs were up-regulated, and 56 miRNAs were down-regulated in the hypoxic conditions (Figure 7).

\section{miR-873-5p May Play a Key Role in the Regulation of MDR1 and PXR under}

Hypoxia.let-7f-5p, let-7g-5p, miR-522-3p, miR-873-5p, miR-148b-3p, and miR-148a-3p were regarded as possible regulators when MDR1 and PXR changed under hypoxia by using Miranda, a microRNA target prediction database, in which we found binding sites of let-7f-5p, let-7g-5p, miR-522-3p, miR-873-5p, miR-148b-3p, and miR-148a-3p in PXR 3' UTR. As shown in Figure 8, the mRNA expression of let-7f-5p, let-7g-5p, miR-522-3p, miR-873-5p, miR-148b-3p, and miR-148a-3p significantly decreased in hypoxic conditions. According to the literature reports (Wu et al., 2016), miR-873-5p can regulate MDR1. Therefore, miR-873-5p was selected for the transfection experiment.

Identification of miR-873-5p that regulates the expression of MDR1 and PXR. To investigate whether miR-873-5p has a function in the down-regulation of MDR1 and PXR expression, Caco- 2 cells were cultured in a medium, and then cells were transfected with mimics and inhibitors of miR-873-5p or NC. Figure 9 shows that miR-873-5p expression significantly increased in the mimic group, but decreased in the inhibitor group. The expressions of mRNA and protein of MDR1 and PXR increased after the treatment of Caco-2 cells with an inhibitor of miR-873-5p and decreased in the mimic group.

\section{Discussion}

Drug metabolizing enzymes and transporters are the main factors affecting drug 
metabolism. In our previous studies, we found that high-altitude hypoxia affects the activity and expression of cytochrome P450 (Duan et al., 2020; Duan et al., 2021; Zhou et al., 2018). To date, only a few reports have addressed the ways to resolve the problem of changes in the functions and expression levels of drug transporters under high altitude hypoxic environments. To further study the effects of high-altitude hypoxia on drug transporters, changes in the functions and expression levels of MDR1, MRP2, BCRP, PEPT1, and OATP2B1 were examined in rats and Caco-2 cells. The results suggested that high-altitude hypoxia increased the expression and activity of most drug transporters.

Fradette et al. found that hypoxia increased the protein and mRNA expression of P-gp, but hypoxia did not affect the mRNA expression of BCRP in rats subjected to a $\mathrm{Fio}_{2}$ of $8 \%$ for $48 \mathrm{~h}$ compared to those in rabbits breathing 21\% Fio 2 (Fradette et al., 2007). Lazarowski et al. showed that hypoxia induced neuronal MDR1 expression after experimental focal hypoxia by local injection of $\mathrm{CoCl}_{2}$ into the frontoparietal cortex in male adult rats (Lazarowski et al., 2007). Zhang et al. found that MDR1 was significantly changed and directly regulated by Kruppel Like Factor 8 (KLF8) under hypoxia (Zhang et al., 2014), which is consistent with our findings. Another study found that the mRNA expression of MDR1 was decreased by hypoxia, and the $\mathrm{P}_{\text {eff }}$ value of the substrate was significantly increased ( $\mathrm{Li}$ et al., 2016). Models of hypoxia that are induced by low-pressure cabins or chemical methods can only simulate hypoxia, and these methods cannot simulate the conditions of hypothermia, dry climate, or intense radiation, which means these methods cannot reflect a real high altitude environment.

The structure and function of Caco- 2 cells are similar to intestinal epithelial cells, and 
they share the same results in studies concerning in vivo and in vitro drug transporter functions. Efflux transporters, such as MDR1, MRP2, and BCRP, play the role of an intestinal barrier in the small intestine, discharging intracellular substances into the intestinal cavity, while uptake transporters, such as PEPT1 and OATP2B1, are widely expressed in the small intestine and are capable of promoting the absorption of drugs (Liu et al., 2019). Under the influence of hypoxic conditions, the improved efflux functions of MDR1 and BCRP may weaken drug absorption and cause drug resistance, whereas the enhanced uptake functions of PEPT1 and OATP2B1 may promote drug absorption as well as improve bioavailability. The significantly decreased efflux function of MRP2 may reduce the occurrence of multidrug resistance.

Studies have reported an association between the uptake activity of PEPT1 and $\mathrm{pH}$. If the $\mathrm{pH}$ of the drugs that are absorbed in the small intestine can be adjusted to the most appropriate range of PEPT1, their bioavailability can be improved (Wu et al., 2020). Firstly, the structure of intestinal microbiota changed significantly under hypoxic conditions, and intestinal $\mathrm{pH}$ was also changed accordingly (Liu et al., 2021), which significantly affected the uptake activity of PEPT1. Secondly, the results of this study showed that different oxygen concentrations had different effects on the protein expression of PEPT1. The 2\%-24h group had the most significant effect, followed by 5\%-48h, $5 \%-24 \mathrm{~h}, 5 \%-12 \mathrm{~h}$, and 5\%-6h group. If the optimal oxygen concentration and the optimal $\mathrm{pH}$ could be found, the bioavailability of PEPT1 substrate drugs could be significantly improved, and the problem of the low absorption rate of some oral drugs could be solved. This experiment only studied the effects of different oxygen concentrations on the protein 
expression of transporters and not on the functions of transporters, which will be covered in subsequent experiments.

The expression regulation of genes is a complex process that comprises transcriptional regulation and post-transcriptional regulation. The former is further divided into DNA regulation at the genetic level and epigenetic regulation, while the latter is further divided into the regulation of RNA processing and maturation process, translational regulation, and regulation of protein processing (Zhu et al., 2012). In this experiment, the proteins of MDR1, MRP2 and OATP2B1 have different variation trends of expression from those of mRNA, probably due to post-transcriptional regulation.

Bioinformatics analysis showed that multiple miRNAs could target the PXR gene, and PXR is an important member of the nuclear receptor family. Studies have shown a strong link between PXR and MDR1 (Li et al., 2017; Gu et al., 2013). Previous studies by the authors have demonstrated a significant reduction of PXR expression in rats and HepG2 cells under hypoxic conditions (Duan et al., 2020). This study showed that the expression of PXR in Caco-2 cells under hypoxic conditions was also reduced significantly, which is in line with the previous studies. It is important to study the significance of the relationship of the miRNA-PXR-MDR1 axis.

A high-throughput sequencing technique was adopted to detect the changes of miRNAs under hypoxic conditions. Eighty-three miRNAs were observed to be changed significantly, of which the expression of 27 miRNAs was found to be increased, and the expression of 56 was found to be decreased. We conducted target prediction on those miRNAs using miRanda, and selected let-7f-5p, let-7g-5p, miR-522-3p, miR-873-5p, 
miR-148a-3p and miR-148b-3p for their potentials to interact with PXR. qPCR was then used to demonstrate the expression reduction of let-7f-5p, let-7g-5p, miR-522-3p, miR-873-5p, miR-148a-3p and miR-148b-3p under hypoxic condition. Wu et al. (Wu et al., 2016) investigated the multidrug resistance mechanism in ovarian cancer cells and found that miR-873 mediated multidrug resistance by targeting MDR1, confirming that miR-873 could regulate the expression of MDR1. Takagi et al. (Takagi et al., 2008) confirmed that miR-148a has a regulatory effect on PXR. A drug resistance study of HT29 colon cancer cells found that miR-522 could target ABCB5 to reverse amycin-induced drug resistance (Yang et al., 2015). The regulatory effects of let-7f, let-7g, miR-522, and miR-148 on MDR1 have not been reported yet. According to literature reports and bioinformatics analysis results, we found that miR-873-5p might target MDR1 and PXR to regulate drug metabolism.

miR-873-5p-mimic and inhibitor transfection cells were used to verify the regulatory effects of miR-873-5p on PXR and MDR1. It was found that PXR expression significantly decreased in miR-873-5p over-expression cells and significantly increased in miR-873-5p low-expression cells, confirming that miR-873-5p could negatively regulate PXR expression. Numerous studies have confirmed that the dimer of the nuclear receptor PXR and its molecular chaperone directly bind the DNA to MDR1 or recruit other DNA transcription factors to activate the genetic transcription of MDR1 (Gu et al., 2013; Feng et al., 2018; Moscovitz et al., 2018). According to the above-mentioned results, this study speculates that miR-873-5p may target PXR to regulate the expression of MDR1. However, Figure 3 shows the opposite trend as over-expression of MDR1 
occurs along with down-regulation of PXR. It is suggested that the progress of drug transporters regulation under hypoxia might involve several signaling pathways and not a single signaling pathway; this is an integral component of gene regulatory networks and requires further study. In miR-873-5p over-expression and low-expression cells, MDR1 expression was also significantly decreased and increased, respectively, confirming that miR-873-5p also negatively regulated MDR1 expression in a direct manner. Besides, in the family of nuclear receptors, constitutive androstane receptor (CAR) could regulate MRPs (Lv et al., 2020), PXR could regulate MRPs (Mazerska et al., 2016), farnesoid X receptor (FXR) could regulate OATPs (Malagnino et al., 2019), and hepatocyte nuclear factor 4-alpha (HNF4 $\alpha$ ) culd regulate the expression of MDR1 (Vagnerová et al., 2019). Furthermore, nuclear receptors could also interact with each other. For example, FXR and peroxisome proliferator-activated receptor (PPAR) could interact (Li et al., 2020), and HNF4 $\alpha$ could regulate the expression of PXR, CAR, and hepatocyte nuclear factor 1-alpha (HNF1 $\alpha$ ) (Pavek et al., 2016; Tian et al., 2018; Rosenthal et al., 2019); such an interaction greatly complicates the regulation of drug transporters. Apart from the regulatory effect of miR-873-5p on MDR1 confirmed by this study, miR-27a, miR-145, miR-491, etc., could all act on MDR1 (Shi et al., 2020; Kong et al., 2019; Zhao et al., 2017). It was observed that miRNA had a regulatory effect on CAR, and it is also interesting to note that CAR could, in turn, down-regulate the expression of miRNA, forming a two-way regulation (Kazantseva et al., 2015). The regulation of multiple miRNAs on transporters and nuclear receptors, the interactions among nuclear receptors, the regulation of nuclear receptors on transporters, and the negative feedback of nuclear 
receptors on miRNAs constitute a multi-factor, multi-target, interactive mechanism of drug transporters regulation, with miRNA being the key regulatory factor.

In vivo experiments have confirmed that the transport function of MDR1 in small intestines of rats significantly increased under high altitude hypoxic environment. In vitro experiments have proven that the protein and mRNA expressions of MDR1 significantly increased and the efflux activity improved considerably under hypoxic conditions. The results mentioned above suggest that hypoxia is an inducer of MDR1 and may lead to drug interactions. Tumor cells are also a micro-hypoxic environment and an important reason for the occurrence of multidrug resistance. The increase of MDR1 under high altitude hypoxic conditions may also enhance the incidence of multidrug resistance and reduce the efficacy. Therefore, high-altitude hypoxia may not only affect the physiological disposition of drugs but also facilitate interactions between drugs and increase the incidence of multidrug resistance.

This experiment determined MDR1 protein and mRNA expressions in miR-873-5p over-expression and low-expression Caco-2 cells, respectively, but did not determine the transporter performance of MDR1. Our future research will focus on establishing miR-873-5p over-expression and low-expression Caco-2 monolayer models under hypoxic conditions, and transport experiments will also be conducted on MDR1 substrate drugs to confirm further whether miR-873-5p targets MDR1 to regulate the metabolic process of drugs. MDR1 is a key drug transporter in the liver, kidneys, and intestine. It can pump intracellular drugs out of cells with the help of adenosine triphosphate, thereby reducing the concentration of intracellular drugs (Zhang et al., 2020). However, MRP2, 
BCRP, PEPT1, and OATP2B1 also play a key role in regulating the physiological disposition of drugs under hypoxic conditions. Whether miRNA target MRP2, BCRP, PEPT1, and OATP2B1 is still unclear, which needs further study.

The results of this study may be helpful for rational pharmaceutical use in high-altitude environments. It is suggested that patients should be closely monitored when they are living in or traveling to high-altitude areas, and the dosages of some drugs that are transported by MDR1, MRP2, BCRP, PEPT1, and OATP2B1 should be reevaluated by therapeutic drug monitoring (TDM) .

\section{Authors' Contributions}

Xiang Yang, Yabin, and Xue participated in the research design. Yabin, Xue, JianXin, Yang, Wenqi, Junbo, and Linli conducted experiments. Guiqin and Qian contributed new reagents or analytic tools. Xiang Yang and Yabin performed data analysis. Xiang Yang, Yabin, and Xue drafted the manuscript.

\section{References}

Anjana GV, Krishna K, and Joginder D (2012) Effect of intermittent hypobaric hypoxia on efficacy and clearance of drug. Indian J Med Res 135: 211-216.

Arancibia A, Paulos C, Chavez J, and Ritschel WA (2003) Pharmacokinetics of lithium in healthy volunteers after exposure to high altitude. Int J Clin Pharmacol Ther 41: $200-206$.

Chen XM, Li JS, Li W, Han L, Liu XH, Di LQ, and Cai BC (2010) Intestinal absorption of the effective components of Schisandra chinensis Baill by rats single-pass perfusion 
in situ. Acta Pharmaceutica Sinica 45: 652-658.

Duan YB, Zhu JB, Yang JX, Gu WQ, Bai X, Liu GQ, Li XY. (2021) A Decade's Review of miRNA: a Center of Transcriptional Regulation of Drug-Metabolizing Enzymes and Transporters Under Hypoxia. Curr Drug Metab 22: 709-725.

Duan YB, Zhu JB, Yang JX, Liu GQ, Bai X, Qu Ning, Wang XJ, and Li XY (2020) Regulation of High-Altitude Hypoxia on the Transcription of CYP450 and UGT1A1 Mediated by PXR and CAR. Front Pharmacol 11: 1574176.

Eide RP, and Asplund CA (2012) Altitude illness: update on prevention and treatment. Curr Sports Med Rep 11: 124-130.

Feng D, Tang T, Fan R, Luo J, Cui H, Wang Y, and Gan P (2018) Gancao (Glycyrrhizae Radix) provides the main contribution to Shaoyao-Gancao decoction on enhancements of CYP3A4 and MDR1 expression via pregnane $\mathrm{X}$ receptor pathway in vitro. BMC Complement Altern Med 18: 345.

Fradette C, Batonqa J, Teng S, Piquette MM, and du Souich P (2007) Animal models of acute moderate hypoxia are associated with a down-regulation of CYP1A1, 1A2, 2B4, 2C5, 2C16 and up-regulation of CYP3A6 and P-glycoprotein in liver. Drug Metab Dispos 35: 765-771.

Fradette C, Bleau AM, Pichette V, Chauret N, and du Souich P (2002) Hypoxia-induced down-regulation of CYP1A1/1A2 and up-regulation of CYP3A6 involves serum mediators. Br J Pharmacol 137: 881-891.

Fradette C, and du Souich P (2004) Effect of hypoxia on cytochrome P450 activity and expression. Curr Drug Metab 5: 257-271. 
Fujiwara H, Hashikawa-Hobara N, Wake Y, Takatori S, Goda M, Higuchi H, Zamami Y, Tangsucharit P, and Kawasaki H (2012) Neurogenic Vascular Responses in Male Mouse Mesenteric Vascular Beds. J Pharmacol Sci 119: 260-270.

Gilbert DL (1983) The first documented description of mountain sickness: the Andean or pariacaca story. Resp Physiol 52: 327-347.

Gonzalez-Alvarez I, Gonzalez-Alvarez M, Oltra-Noguera D, Merino V, Tõkési N, Ovádi J, and Bermejo M (2009) Unique pharmacology of KAR-2, a potential anti-cancer agent: absorption modelling and selective mitotic spindle targeting. Eur J Pharm Sci 36: $11-19$.

Gu L, Chen J, Synold TW, Forman BM, and Kane SE (2013) Bioimaging real-time PXR-dependent mdr1a gene regulation in mdr1a.fLUC reporter mice. J Pharmacol Exp Ther 45: 438-445.

He Y, Chevillet JR, Liu G, Kim TK, and Wang K (2015) The effects of microRNA on the absorption, distribution, metabolism and excretion of drugs. $\mathrm{Br} J$ Pharmacol 172: 2733-2747.

Huo X, Liu Q, Wang C, Meng Q, Sun H, Peng J, Ma X, and Liu K (2013) Enhancement effect of P-gp inhibitors on the intestinal absorption and antiproliferative activity of bestatin. Eur J Pharm Sci 50: 420-428.

Imray C, Wright A, Subudhi A, and Roach R (2010) Acute mountain sickness: pathophysiology, prevention, and treatment. Prog Cardiovasc Dis 52: 467-484.

Jennifer PS, Michael M, and Wenyi G (2017) Drug resistance and cancer stem cells: the shared but distinct roles of hypoxia-inducible factors HIF $1 \alpha$ and HIF2 $\alpha$. Clin Exp 
Pharmacol Physiol 44: 153-161.

Jones DP, Aw TY, and Shan X (1989) Drug metabolism and toxicity during hypoxia. Drug Metab Rev 20: 247-260.

Kazantseva YA, Yarushkin AA, Mostovich LA, Pustylnyak YA, and Pustylnyak VO (2015) Xenosensor CAR mediates down-regulation of miR-122 and up-regulation of miR-122 targets in the liver. Toxicol Appl Pharmacol 288: 26-32.

Kong J, Qiu Y, Li Y, Zhang HJ, and Wang WP (2019) TGF- $\beta 1$ elevates P-gp and BCRP in hepatocellular carcinoma through HOTAIR/miR-145 axis. Biopharm Drug Dispos 40: 70-80.

Kurdi J, Maurice H, El-Kadi AO, Ong H, Dalkara S, Bélanger PM, and Souich P (1999) Effect of hypoxia alone or combined with inflammation and 3-methylcholanthrene on hepatic cytochrome P450 in conscious rabbits. Br J Pharmacol 128: 365-373.

Lazarowski A, Caltana L, Merelli A, Rubio MD, Ramos AJ, and Brusco A (2007) Neuronal mdr-1 gene expression after experimental focal hypoxia: a new obstacle for neuroprotection? J Neurol Sci 258: 84-92.

Li WB, Luo BF, Wang R, Lu H, Wang C, Zhao AP, and Jia ZP (2016) Changes of P-gp expression in rats' small intestine and effects on uptake of levofloxacin after acute exposure to hypoxia. Acta Pharm Sin 51: 1412-1416.

Li XY, Gao F, Li ZQ, Guan W, Feng WL, and Ge RL (2009) Comparison of the pharmacokinetics of sulfamethoxazole in male Chinese volunteers at low altitude and acute exposure to high altitude versus subjects living chronically at high altitude. Clin. Ther 31: 2744-2754. 
Li XY, Liu YN, Wang XJ, Zhu JB, Yuan M, Li YP, and Li YF (2012) Comparison of the pharmacokinetics of sulfamethoxazole in native Han and Tibetan male Chinese volunteers living at high altitude. Eur J Drug Metab Pharmacokinet 37: 263-269.

Li XY, Liu YN, Yuan M, Li YP, Yang YZ, and Zhu JB (2012) Effect of high altitude hypoxia on the activity and protein expression of CYP2C9 and CYP2C19. Acta Pharm Sin 47: 188-193.

Li XY, Wang XJ, Li YP, Zhu JB, Su XD, Yao XC, Fan XR, and Duan YB (2014a) The Activity, Protein, and mRNA Expression of CYP2E1 and CYP3A1 in Rats after Exposure to Acute and Chronic High Altitude Hypoxia. High Alt Med Biol 15: 491 496.

Li XY, Wang XJ, Li YP, Yuan M, Zhu JB, Su XD, Yao XC, Fan XR, and Duan YB (2014b) Effect of exposure to acute and chronic high altitude hypoxia on the activity and expression of CYP1A2, CYP2D6, CYP2C9, CYP2C19 and NAT2 in rats. Pharmacology 93: 76-83.

Li Y, Liu JW, Liu KT, Wang YL, Zhou YP, Xu Y, and Li XM (2017) Intestinal Absorption Characters of Mosapride Citrate Using Caco-2 Cells and Single-Pass Intestinal Perfusion Methods. Chin Pharm J 52: 1519-1524.

Li YH, Huang B, Wei XH, Wen JH, Zhong GP, Huang M, and Bi HE (2017) Regualation of P-glycoprotein gene expression by PKC/NF-кB-PXR/. Acta Pharm Sin 52: 51-57.

Li YY, Cao CY, Zhou YL, Nie YQ, Cao J, and Zhou YJ (2020) The roles and interaction of FXR and PPARs in the pathogenesis of nonalcoholic fatty liver disease. Arab $J$ Gastroenterol 21: 162-168. 
Liu GQ, Bai X, Duan YB, Zhu JB, Yang JX, Wang Qian, Zhou Y, Gu, WQ, and Li XY (2021) Changes in the intestinal flora of rats under high altitude hypoxia. Acta Pharm Sin 56: 1100-1108.

Liu H, Liu L, Li J, Mei D, Duan R, Hu N, Guo H, Zhong Z, and Liu X. (2012) Combined contributions of impaired hepatic CYP2C11 and intestinal breast cancer resistance protein activities and expression to increased oral glibenclamide exposure in rats with streptozotocin-induced diabetes mellitus. Drug Metab Dispos 40: 1104-1112.

Liu XD (2019) Intestinal Transporters-Associated Drug Absorption and Toxicity. Adv Exp Med Biol 1141: 361-406.

Lu TX, Rothenberg ME (2018) MicroRNA. J Allergy Clin Immunol. 141: 1202-1207.

Lv C, and Huang L (2020) Xenobiotic receptors in mediating the effect of sepsis on drug metabolism. Acta Pharm Sin B 10: 33-41.

Mairbaurl H (1994) Red blood cell function in hypoxia at altitude and exercise. Int J Sports Med 15: 51-63.

Malagnino V, Hussner J, Issa A, Midzic A, Meyer Zu. and Schwabedissen HE (2019) OATP1B3-1B7, a novel organic anion transporting polypeptide, is modulated by FXR ligands and transports bile acids. Am J Physiol Gastrointest Liver Physiol 317: G751-G762.

Mazerska Z, Mróz A, Pawłowska M, and Augustin E (2016) The role of glucuronidation in drug resistance. Pharmacol Ther 159: 35-55.

Moriguchi J, Kato R, Nakagawa M, Hirotani Y, Ijiri Y, and Tanaka K (2007) Effects of lipopolysaccharide on intestinal P-glycoprotein expression and activity. Eur $J$ 
Pharmacol 565: 220-224.

Moscovitz JE, Kalgutkar AS, Nulick K, Johnson N, Lin Z, Goosen TC, Weng Y (2018) Establishing Transcriptional Signatures to Differentiate PXR-, CAR-, and AhR-Mediated Regulation of Drug Metabolism and Transport Genes in Cryopreserved Human Hepatocytes. J Pharmacol Exp Ther 365: 262-271.

Netzer N, Strohl K, Faulhaber M, Gatterer H, and Burtscher M (2013) Hypoxia-related altitude illnesses. J Travel Med 20: 247-255.

Nivoix DY, Levêque D, Herbrecht R, Koffel JC, and Beretz L (2008) Ubeaudsequier G. The Enzymatic Basis of Drug-Drug Interactions with Systemic Triazole Antifungals. Clin Pharmacokinet 47: 779-792.

Pavek P (2016) Pregnane X Receptor (PXR)-Mediated Gene Repression and Cross-Talk of PXR with Other Nuclear Receptors via Coactivator Interactions. Front Pharmacol 7: 456.

Qiao YJ, Wang XJ, Xin YY, Nian YQ, Yang JX, Duan YB, and Li XY (2019) Effect of x-ray irradiation on pharmacokinetics of irinotecan hydrochloride and expression of CES1 and CYP3A1 in rats. Fundam Clin Pharmacol 33: 558-566.

Rashid M, Fahim M, and Kotwani A (2013) Efficacy of tadalafil in chronic hypobaric hypoxia-induced pulmonary hypertension: possiblemechanisms. Fundam Clin Pharmacol 27: 271-278.

Rosenthal SB, Bush KT, and Nigam SK (2019) A Network of SLC and ABC Transporter and DME Genes Involved in Remote Sensing and Signaling in the Gut-Liver-Kidney Axis. Sci Rep 9: 11879. 
Shi X, Valizadeh A, Mir SM, Asemi Z, Karimian A, Majidina M, Safa A, and Yosefi B (2020) miR-29a reverses P-glycoprotein-mediated drug resistance and inhibits proliferation via up-regulation of PTEN in colon cancer cells. Eur J Pharmacol 880: 173138.

Simon RB, and Simon DA (2014) Illness at high altitudes. Nursing 44: 36-44.

Takagi S, Nakajima M, Mohri T, and Yokoi T (2008) Post-transcriptional regulation of human pregnane $\mathrm{X}$ receptor by micro-RNA affects the expression of cytochrome P450 3A4. J Biol Chem 283: 9674-9680.

Tian J, Marino R, Johnson C, and Locker J (2018) Binding of Drug-Activated CAR/Nr1i3 Alters Metabolic Regulation in the Liver. iScience 9: 209-228.

Vagnerová K, Ergang P, Soták M, Balounová K, Kvapilová P, Vodička M, and Pácha J (2019) Diurnal expression of ABC and SLC transporters in jejunum is modulated by adrenalectomy. Comp Biochem Physiol C Toxicol Pharmacol 226: 108607.

Vesell ES (1977) Genetic and environmental factors affecting drug disposition in man. Clin Pharmacol Ther 22: 659-679.

Wu DD, Li XS, Meng XN, Yan J, and Zong ZH (2016) MicroRNA-873 mediates multidrug resistance in ovarian cancer cells by targeting ABCB1. Tumour Biol 37: 10499-10506.

Wu Q, He X, Zhou S, Shi F, and Lu Y (2020) Role of PEPT1in the transport of cinnabar in Caco-2 cells. Toxicol. In Vitro 63: 104747.

Xiang D, Fan L, Hou XL, Xiong W, Shi CY, Wang WQ, and Fang JG (2018) Uptake and Transport Mechanism of Dihydromyricetin Across Human Intestinal Caco-2 Cells. $J$ 
Food Sci 83: 1941-1947.

Yang G, Jiang O, Ling D, Jiang X, Yuan P, Zeng G, Zhu J, Tian J, Weng Y, and Wu D (2015) MicroRNA-522 reverses drug resistance of doxorubicin-induced HT29 colon cancer cell by targeting ABCB5. Mol Med Rep 12: 3930-3936.

Zhang H, Sun L, Xiao X. Xie R, Liu C, Wang Y, Wei Y. Zhang H, and Liu L (2014) Kruppel-like factor 8 contributes to hypoxia-induced MDR in gastric cancer cells. Cancer Sci 105: 1109-11015.

Zhang JL, Zhu JB, Yao XC, Duan YB, Zhou XJ, Yang M, and Li XY (2016) Pharmacokinetics of Lidocaine Hydrochloride Metabolized by CYP3A4 in Chinese Han Volunteers Living at Low Altitude and in Native Han and Tibetan Chinese Volunteers Living at High Altitude. Pharmacology 97: 107-113.

Zhang JH, Zhang MX, Zhang JM, Wang R (2020) Enhanced P-glycoprotein expression under high-altitude hypoxia contributes to increased phenytoin levels and reduced clearance in rats. Eur J Pharm Sci 153: 105490.

Zhang JH, Zhang JM, Wang R, Jia ZP (2019) Effects of Gut Microbiota on Drug Metabolism and Guidance for Rational Drug Use Under Hypoxic Conditions at High Altitudes. Curr Drug Metab 20:155-165.

Zhao Y, Qi X, Chen J, Wei W, Yu C, Yan H, Pu M, Li Y, Miao, Li C, and Ren J (2017) The miR-491-3p/Sp3/ABCB1 axis attenuates multidrug resistance of hepatocellular carcinoma. Cancer Lett. 408: 102-111.

Zhou XJ, Nian YQ, Qiao YJ, Yang M, Xin YY, and Li XY (2018) Hypoxia plays a key role in the pharmacokinetic changes of drugs at high altitude. Curr Drug Metab 19: 960 - 
969.

Zhu YX, Li Y, Zhen XF, and Guo HW (2012). Modern molecular biology pp 300-301, High education press, Beijing. 
Footnotes: This work was supported by the National Natural Science Foundation of China (No. 81760673 and 81460568), the Qinghai Innovation Platform Construction Project (No. 2021-ZJ-T03), and the Key Research Foundation of Development and Transformation of Qinghai Province (2021-SF-158). There is no conflict of interest to disclose. 


\section{Figure Legends}

Figure 1: Expression of MDR1, MRP2, BCRP, PEPT1, and OATP2B1 in rats.

(a) mRNA expression; and (b) Protein expression. Data were expressed as mean $\pm \mathrm{SD}(\mathrm{n}=10)$. The data were analyzed using one-way analysis of variance (ANOVA), followed by post hoc tests using LSD tests. . $P<0.05$ vs. the $\mathrm{P}$ group. The plain group (P, altitude: $\left.390 \mathrm{~m}, \mathrm{PaO}_{2}: 20 \mathrm{kPa}\right)$ : rats living in the city of Xi'an. The acute moderate-altitude hypoxia group ( $\mathrm{AMH}$, altitude: 2,800 m, $\mathrm{PaO}_{2}: 15.1 \mathrm{kPa}$ ) and the chronic moderate-altitude hypoxia group $\left(\mathrm{CMH}\right.$, altitude: 2,800 m, $\left.\mathrm{PaO}_{2}: 15.1 \mathrm{kPa}\right)$ : rats living at the city of Xi'an, but they received a 24-hour acute exposure and a 30-day chronic exposure to a middle altitude area (Gonghe County). The acute high-altitude hypoxia group (AHH, altitude: 4,300 m, $\mathrm{PaO} 2: 12.4 \mathrm{kPa})$ and the chronic high-altitude hypoxia group (CHH, altitude: 4,300 m, $\mathrm{PaO} 2: 12.4 \mathrm{kPa})$ : rats living in the city of Xi'an, but the rats in the AHH group were acutely exposed for $24 \mathrm{~h}$ to high altitudes, and the rats in the $\mathrm{CHH}$ group were chronically exposed for 30 days to high altitudes areas (Maduo County).

Figure 2: Function of MDR1, MRP2, BCRP, PEPT1, and OATP2B1 in rats.

Left panel: Intestinal absorption expressed in $\mathrm{P}_{\text {eff }}$ (the effective permeability coefficient) of rhodamine 123, vincristine, prazosin, ubenimex, and glibenclamide. Right panel: Intestinal absorption expressed in $\mathrm{K}_{\mathrm{a}}$ (the absorption rate constant) of rhodamine 123, vincristine, prazosin, ubenimex, and glibenclamide. Data were expressed as mean \pm SD $(n=6)$. The data were analyzed using a one-way 
analysis of variance (ANOVA), followed by post hoc tests using LSD tests. ${ }^{*} P<0.05$ vs. the P group. The plain group (P, altitude: $390 \mathrm{~m}, \mathrm{PaO}_{2}$ : $20 \mathrm{kPa}$ ): rats living in the city of Xi'an. The acute moderate-altitude hypoxia group $\left(\mathrm{AMH}\right.$, altitude: $\left.2,800 \mathrm{~m}, \mathrm{PaO}_{2}: 15.1 \mathrm{kPa}\right)$ and the chronic moderate-altitude hypoxia group $\left(\mathrm{CMH}\right.$, altitude: $\left.2,800 \mathrm{~m}, \mathrm{PaO}_{2}: 15.1 \mathrm{kPa}\right)$ : rats living in the city of Xi'an, but they received a 24-hour acute exposure and a 30-day chronic exposure to a middle altitude area (Gonghe County). The acute high-altitude hypoxia group (AHH, altitude: 4,300 m, PaO2: 12.4 $\mathrm{kPa})$ and the chronic high-altitude hypoxia group $(\mathrm{CHH}$, altitude: 4,300 m, $\mathrm{PaO} 2: 12.4 \mathrm{kPa})$ : rats living in the city of $\mathrm{Xi}$ 'an, but the rats in the AHH group were acutely exposed $\mathrm{h}$ to high altitudes for 24, and the rats in the CHH group were chronically exposed to high altitudes areas for 30 days (Maduo County).

Figure 3: Expression of MDR1, MRP2, BCRP, PEPT1, and OATP2B1 in Caco-2 cells.

(a) mRNA expression. (b) Protein expression. Normoxia: Caco-2 cells were cultured in a normoxic humidified incubator. Caco-2 cells were exposed to $2 \% \mathrm{O}_{2}$ for $24 \mathrm{~h}(2 \%-24 \mathrm{~h}), 10 \% \mathrm{O}_{2}$ for $24 \mathrm{~h}$ $(10 \%-24 \mathrm{~h}), 5 \% \mathrm{O}_{2}$ for $24 \mathrm{~h}(5 \%-24 \mathrm{~h}), 5 \% \mathrm{O}_{2}$ for $2 \mathrm{~h}(5 \%-2 \mathrm{~h}), 5 \% \mathrm{O}_{2}$ for $6 \mathrm{~h}(5 \%-6 \mathrm{~h}), 5 \% \mathrm{O}_{2}$ for 12 $\mathrm{h}(5 \%-12 \mathrm{~h}), 5 \% \mathrm{O}_{2}$ for $24 \mathrm{~h}(5 \%-24 \mathrm{~h})$, and $5 \% \mathrm{O}_{2}$ for $48 \mathrm{~h}(5 \%-48 \mathrm{~h})$. Data were expressed as mean \pm $\mathrm{SD}(\mathrm{n}=3)$. The data were analyzed using a one-way analysis of variance (ANOVA) followed by post hoc tests using $\operatorname{LSD}$ tests. ${ }^{*} P<0.05$ vs. the normoxia group.

Figure 4: Effect of hypoxia on the uptake of rhodamine 123, vincristine, prazosin, ubenimex, and glibenclamide in Caco-2 cell model.

Caco-2 cells were incubated at $37^{\circ} \mathrm{C}$ with $2 \% \mathrm{O}_{2}$ for $24 \mathrm{~h}$ in the 6-well plates, and then the samples 
were collected at different time points within 120 min. Data were expressed as mean $\pm \operatorname{SD}(n=3)$. The data were analyzed using an independent sample t-test. ${ }^{*} P<0.05$ vs. the normoxia group.

Figure 5: Effect of hypoxia on the transport (AP-BL) of rhodamine 123, vincristine, prazosin, ubenimex, and glibenclamide in Caco-2 cell model.

(a) rhodamine 123; (b) vincristine; (c) prazosin; (d) ubenimex; and (e) glibenclamide. Caco-2 cells were incubated at $37^{\circ} \mathrm{C}$ with $2 \% \mathrm{O}_{2}$ for $24 \mathrm{~h}$ in the apical or basolateral side of the transwell insert, and then the samples were collected at different time points within $120 \mathrm{~min}$. AP-BL: apical-to-basolateral direction transport. Data were expressed as mean \pm SD $(n=3)$. The data were analyzed using an independent sample t-test. ${ }^{*} P<0.05$ vs. the normoxia group.

Figure 6: Effect of hypoxia on the transport (BL-AP) of rhodamine 123, vincristine, prazosin, ubenimex, and glibenclamide in Caco-2 cell model.

(b) rhodamine 123; (b) vincristine; (c) prazosin; (d) ubenimex; and (e) glibenclamide. Caco-2 cells were incubated at $37^{\circ} \mathrm{C}$ with $2 \% \mathrm{O}_{2}$ for $24 \mathrm{~h}$ in the apical or basolateral side of the transwell insert, and then the samples were collected at different time points within 120 min. BL-AP: basolateral-to-apical direction transport. Data were expressed as mean $\pm \mathrm{SD}(\mathrm{n}=3)$. The data were analyzed using an independent sample t-test. ${ }^{*} P<0.05$ vs. the normoxia group.

Figure 7: Expression profiles of miRNA under hypoxic conditions in Caco-2 cells.

(a) microarray heat map; (b) volcano plot; and (c) scatter diagram. Caco-2 cells were incubated at $37^{\circ} \mathrm{C}$ with $2 \% \mathrm{O}_{2}$ for $24 \mathrm{~h}$ in 6-well plates. The expression levels of miRNAs are shown using the indicated 
pseudocolor scale from -10 (green) to 10 (red) relative to the value for Caco-2 cells in the normoxia group. The color represents the relative mRNA expression levels, green indicating down-regulated miRNAs, red indicating up-regulated miRNAs, and black indicating unchanged miRNAs.

Figure 8: The expression of let-7f-5p, let-7g-5p, miR-522-3p, miR-873-5p, miR-148b-3p, and miR-148a-3p under hypoxia.

Caco-2 cells were incubated at $37^{\circ} \mathrm{C}$ with $2 \% \mathrm{O}_{2}$ for $24 \mathrm{~h}$ in 6-well plates. The expressions of let-7f-5p, let-7g-5p, miR-522-3p, miR-873-5p, miR-148b-3p, and miR-148a-3p were detected by qPCR. Data were expressed as mean $\pm \mathrm{SD}(\mathrm{n}=3)$. The data were analyzed using an independent sample t-test. ${ }^{*} P$ $<0.05$ vs. the control group.

Figure 9: miR-873-5p regulates the expression of MDR1 and PXR in Caco-2 cells.

Caco-2 cells were transfected with negative control (NC) RNA, mimics, and inhibitors of miR-873-5p. The mRNA expression of (a) miR-873-5p, (b) MDR1, and (c) PXR was determined by qPCR. (d) Protein expression of MDR1 and PXR was detected by Western-blot. Data were expressed as mean \pm SD $(n=3)$. The data were analyzed using a one-way analysis of variance (ANOVA) followed by post hoc tests using LSD tests. ${ }^{*} P<0.05$ vs. the control group. 


\section{Tables:}

Table 1: The substrates of MDR1, MRP2, BCRP, PEPT1, and OATP2B1.

\begin{tabular}{ccc}
\hline Drug transporters & Substrates & Concentrations \\
\hline MDR1 & Rhodamine 123 & $40 \mu \mathrm{g} / \mathrm{mL}$ (Moriguchi et al., 2007) \\
MRP2 & Vincristine & $20 \mu \mathrm{g} / \mathrm{mL}($ Gonzalez-Alvarez et al., 2009) \\
BCRP & Prazosin & $20 \mu \mathrm{g} / \mathrm{mL}$ (Fujiwara et al., 2012) \\
PEPT1 & Ubenimex & \\
OATP2B1 & Glibenclamide & $20 \mu \mathrm{g} / \mathrm{mL}$ (Huo et al., 2013) \\
\hline
\end{tabular}


Table 2: Primer sequences corresponding to the rat genes examined with a real-time PCR analysis.

\begin{tabular}{|c|c|c|}
\hline Genes & & Primer sequences $\left(5^{\prime}-3^{\prime}\right)$ \\
\hline \multirow{2}{*}{$M D R 1$} & forward & CTCGCTGCTATCATCCACGGAAC \\
\hline & reverse & CGCTGACGGTCTGTGTACTGTTG \\
\hline \multirow{2}{*}{$B C R P$} & forward & TTAGGACTGAAGAGGACGGTGGAG \\
\hline & reverse & TTGCTACAGACACTACGCTTTGGC \\
\hline \multirow{2}{*}{$M R P 2$} & forward & TGGATTCCCTTGGGCTTTCTTTGG \\
\hline & reverse & AACACGACGAACACCTGCTTGG \\
\hline \multirow{2}{*}{ PEPT1 } & forward & CTTCAGGCAGGATGGCTTCTAACC \\
\hline & reverse & AGCAAGGAGGCGAACAGAACATAC \\
\hline \multirow{3}{*}{$O A T P 2 B 1$} & forward & CTGTCTGCCGCTACTATGACCATG \\
\hline & & \\
\hline & reverse & СTCTGCTCTGCTGCCTCAAGATG \\
\hline \multirow{2}{*}{$\beta$-Actin } & forward & TCACCAACTGGGACGATATG \\
\hline & reverse & GTTGGCCTTAGGGTTCAGAG \\
\hline
\end{tabular}


Table 3: Primer sequences corresponding to the Caco-2 cell genes examined with a real-time PCR analysis.

\begin{tabular}{|c|c|c|}
\hline Genes & & Primer sequence $\left(5^{\prime}-3^{\prime}\right)$ \\
\hline \multirow{2}{*}{$M D R 1$} & forward & GATTGCTCACCGCCTGTCCAC \\
\hline & reverse & CGTGCCATGCTCCTTGACTCTG \\
\hline \multirow{2}{*}{$B C R P$} & forward & ATAAATGGAGCACCGCGACCTG \\
\hline & reverse & GCCGAAGAGCTGCTGAGAACTG \\
\hline \multirow{3}{*}{$M R P 2$} & forward & AGCTGAGGCGTCTGGACTCTG \\
\hline & & \\
\hline & reverse & AATCGCTGCTGGTGCTCAAAGG \\
\hline \multirow{2}{*}{ PEPT1 } & forward & ACCTGTCCACCGCCATCTACC \\
\hline & reverse & GAACTTTCCCAGCCACGAGTCG \\
\hline \multirow{2}{*}{ OATP2B1 } & forward & TTCCTGCTGGTGGTCCTGTCC \\
\hline & reverse & TGGCGTAGGAGGCTGTGATGG \\
\hline \multirow{3}{*}{$P X R$} & forward & ATCAAGCGGAAGAAAAGTGAAC \\
\hline & & \\
\hline & reverse & TGTCAAAGGTTTTCATCTGAGC \\
\hline \multirow{3}{*}{$\beta$-Actin } & forward & GGCACTCTTCCAGCCTTCC \\
\hline & & \\
\hline & reverse & GAGCCGCCGATCCACAC \\
\hline
\end{tabular}


Table 4: Primer sequences corresponding to the cell miRNAs examined with a real-time PCR analysis.

\begin{tabular}{ccc}
\hline miRNA & & Primer sequences (5'-3') \\
\hline$l e t-7 f-5 p$ & forward & CGCGCGTGAGGTAGTAGATTGT \\
$l e t-7 g-5 p$ & forward & CGCGCGTGAGGTAGTAGTTTGT \\
$m i R-148 a-3 p$ & forward & GCGCGTCAGTGCACTACAGAA \\
$m i R-148 b-3 p$ & forward & CGCGTCAGTGCATCACAGAA \\
$m i R-522-3 p$ & forward & CGCGAAAATGGTTCCCTTTA \\
$m i R-873-5 p$ & forward & CGCGGCAGGAACTTGTGAG \\
& forward & CTCGCTTCGGCAGCACA \\
\hline 66 & reverse & AACGCTTCACGAATTTGCGT \\
\hline
\end{tabular}



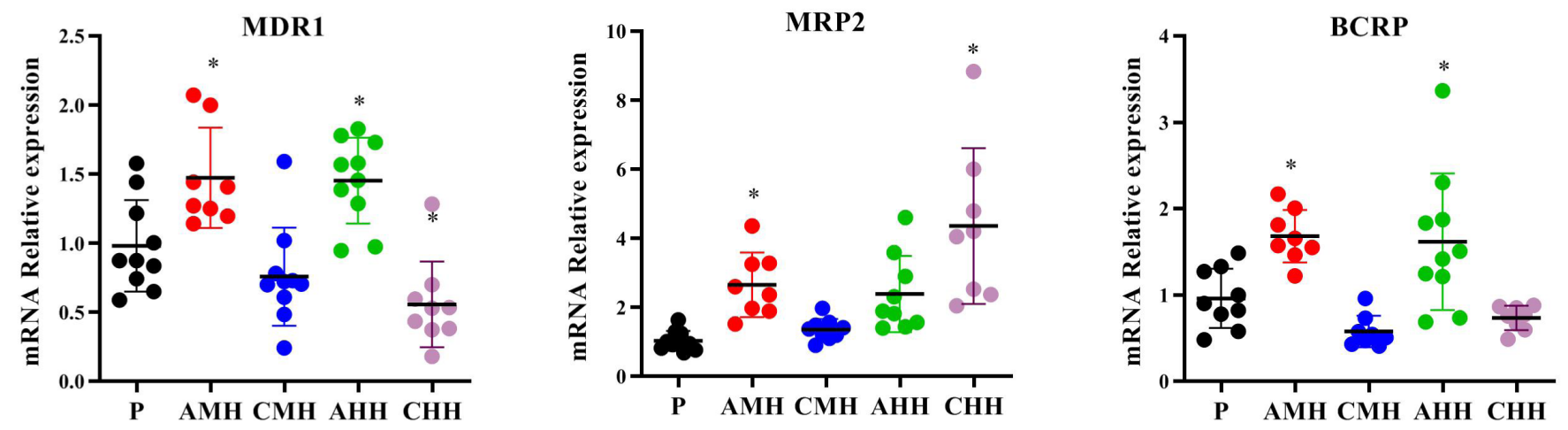

Figure
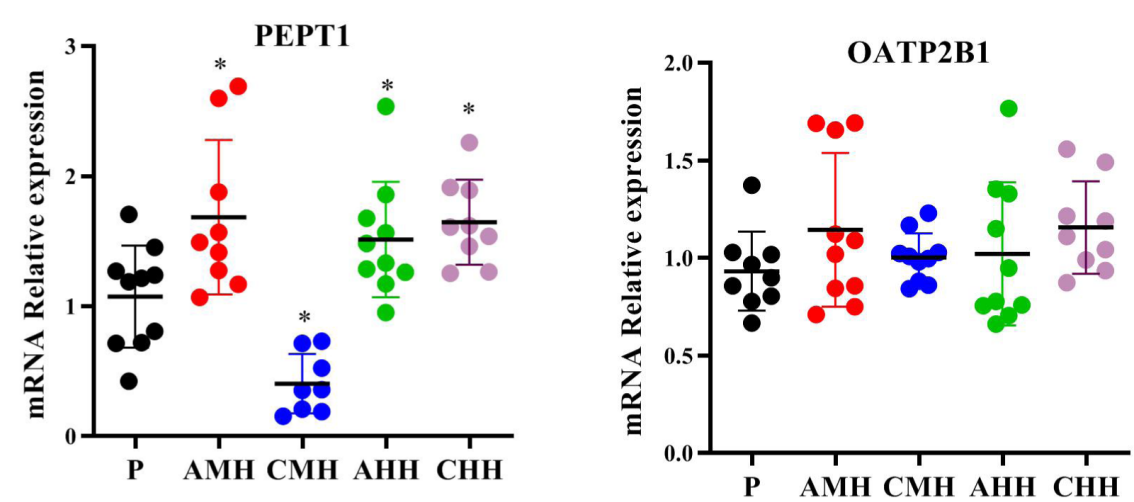

b

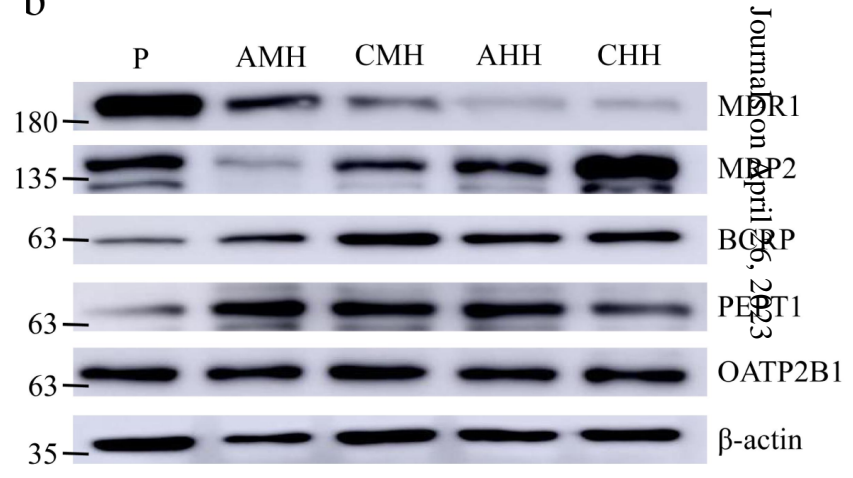



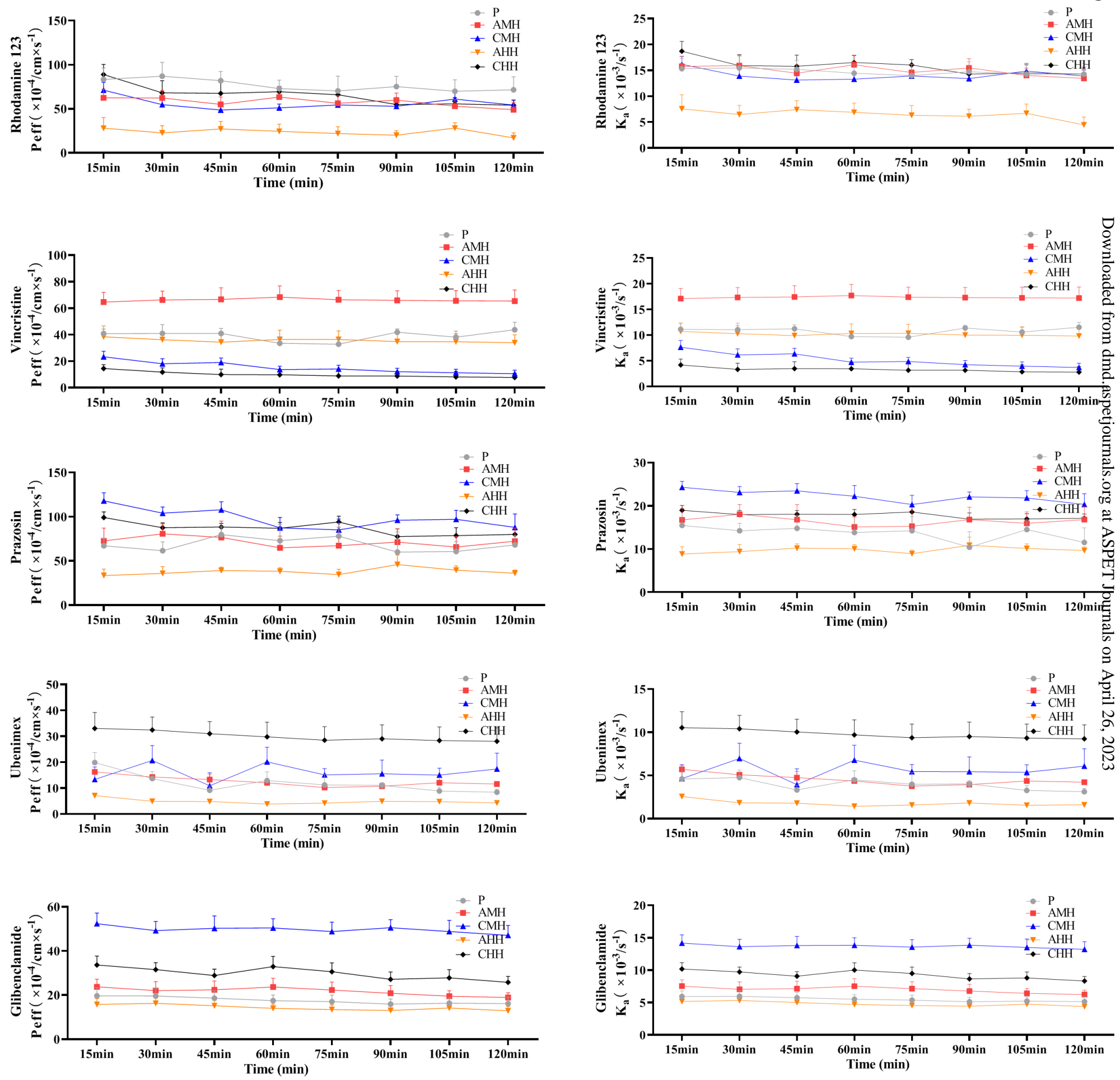
a
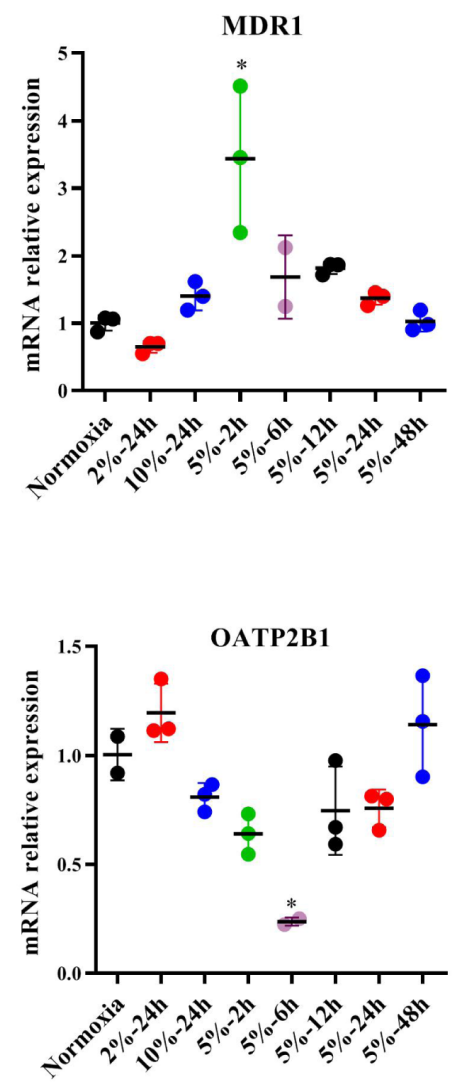
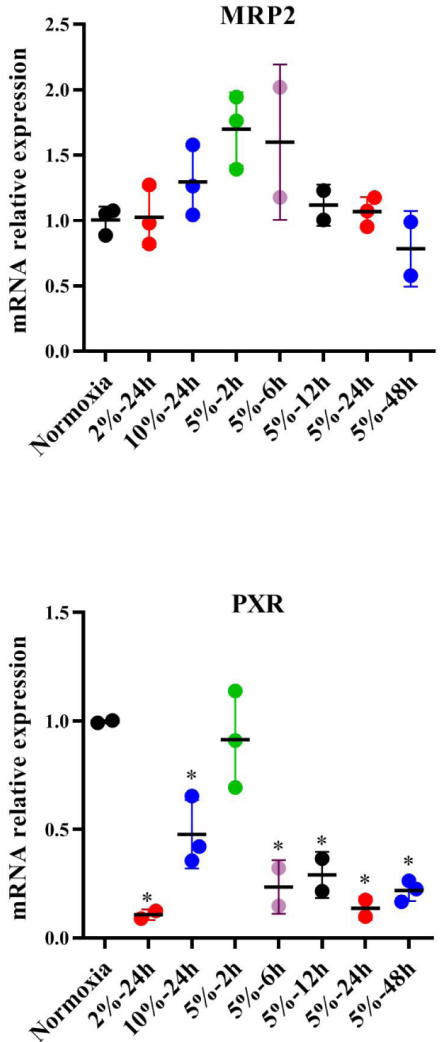

Figure 3
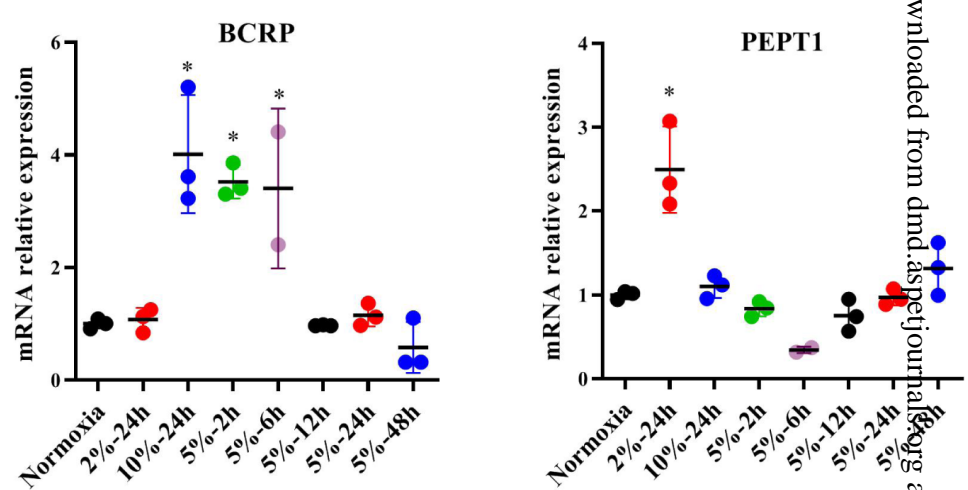

b

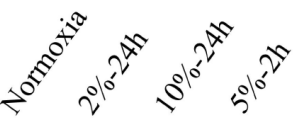

50.

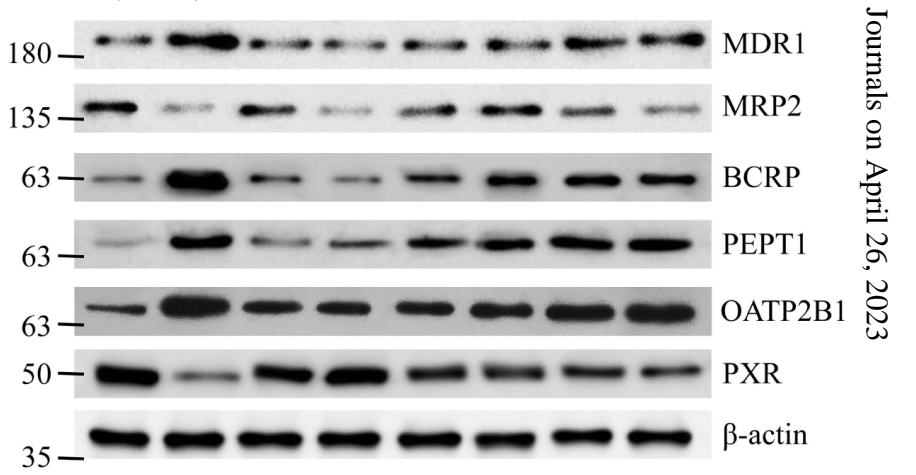



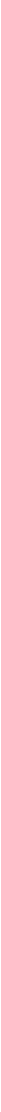

Figure 4 
a

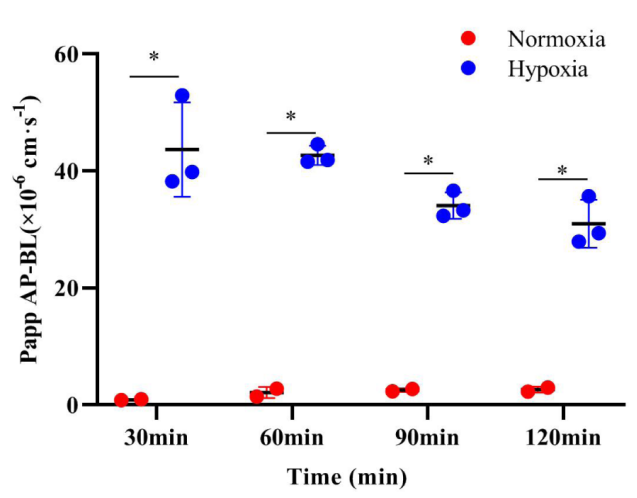

d

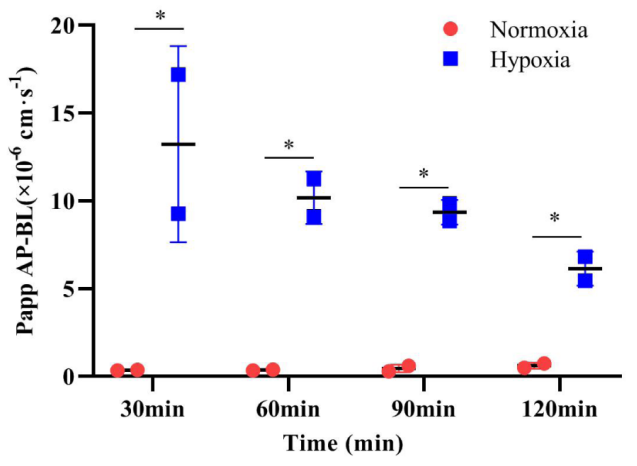

b

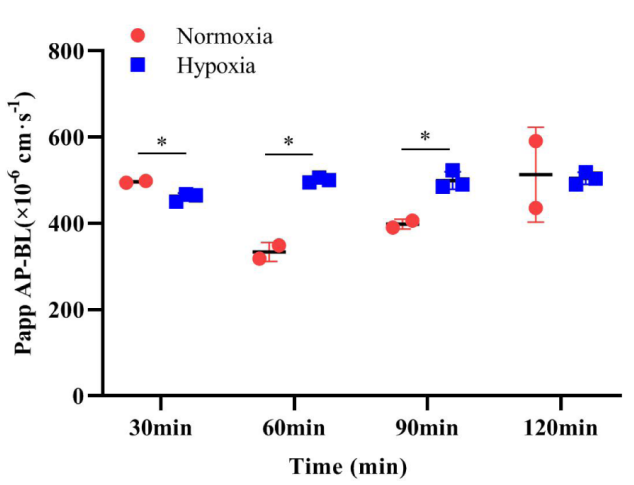

e

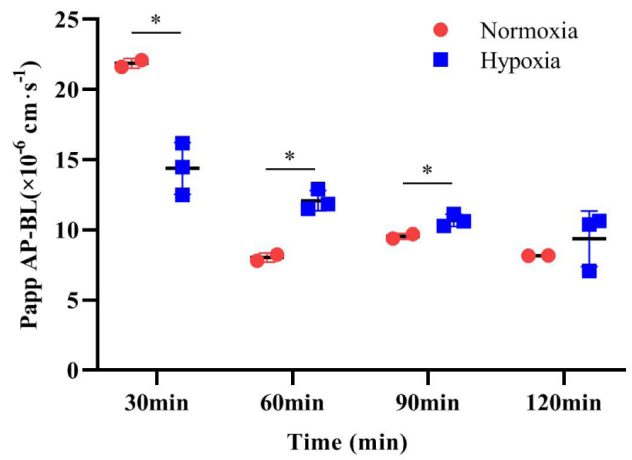

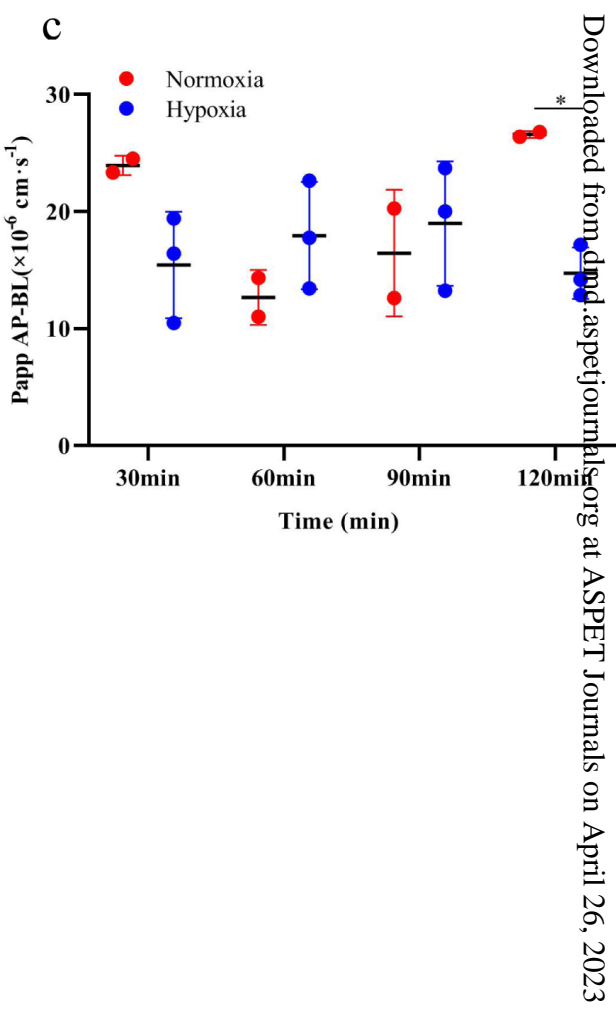

Figure 5 
a

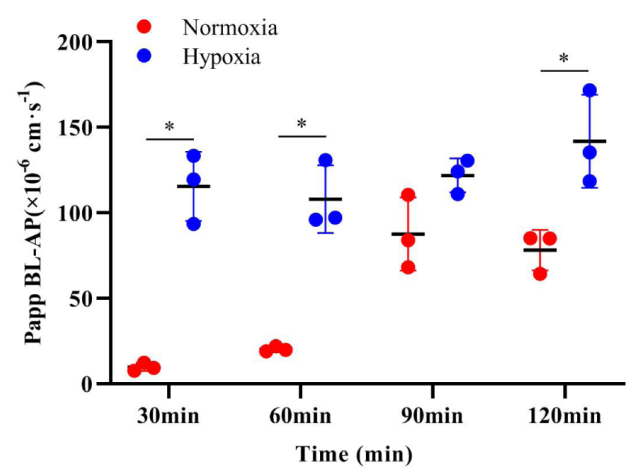

d

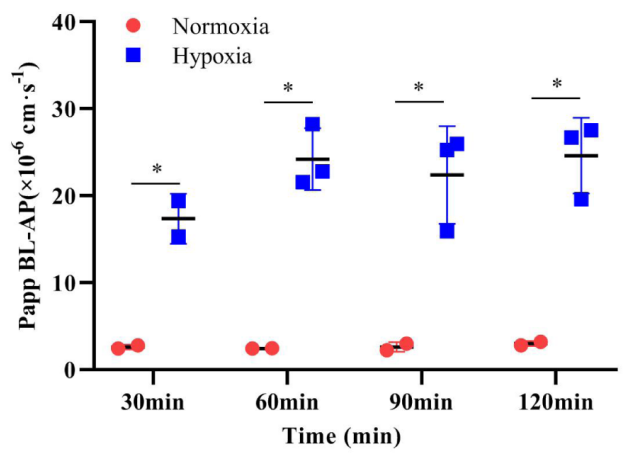

b

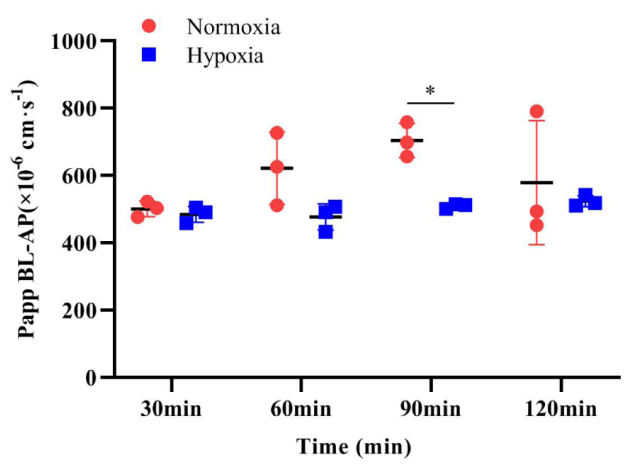

e

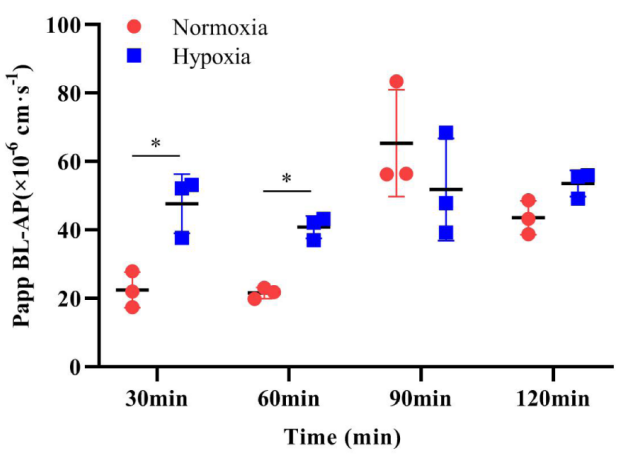

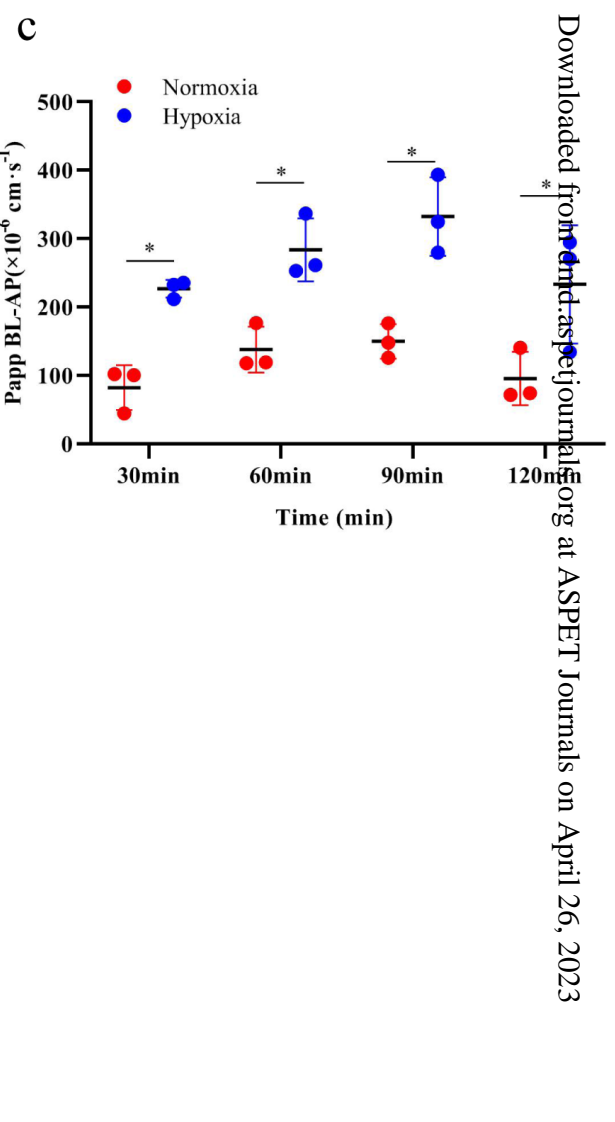

Figure 6 
a

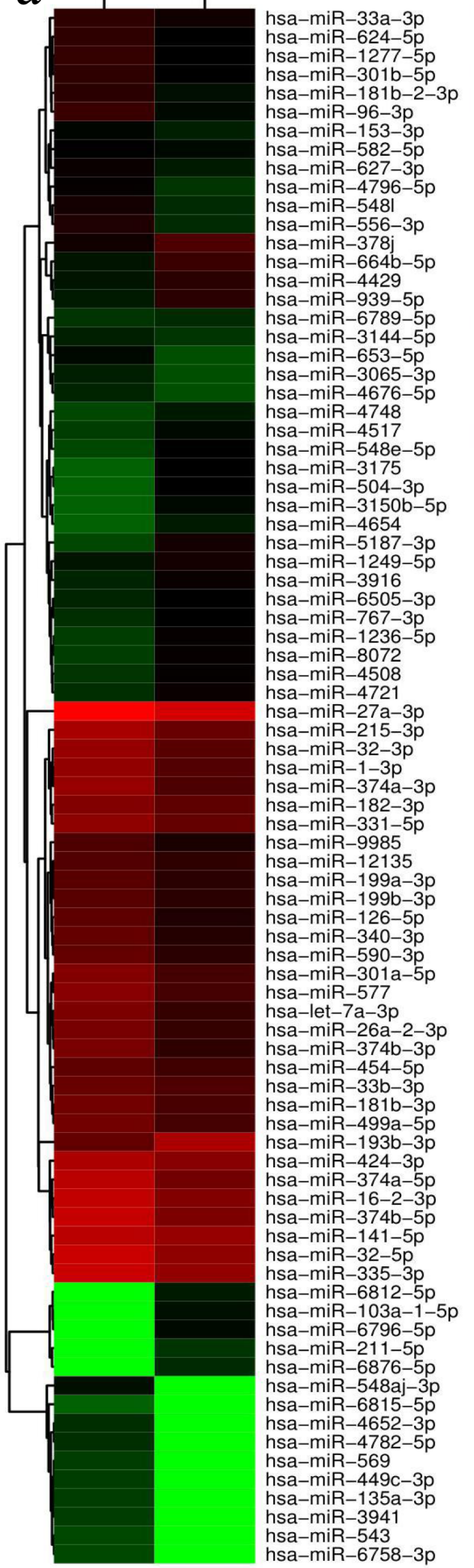

10

5

0

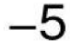

$-10$ b

case1 VS control1, Num.Up $=27$, Num.Down $=56$

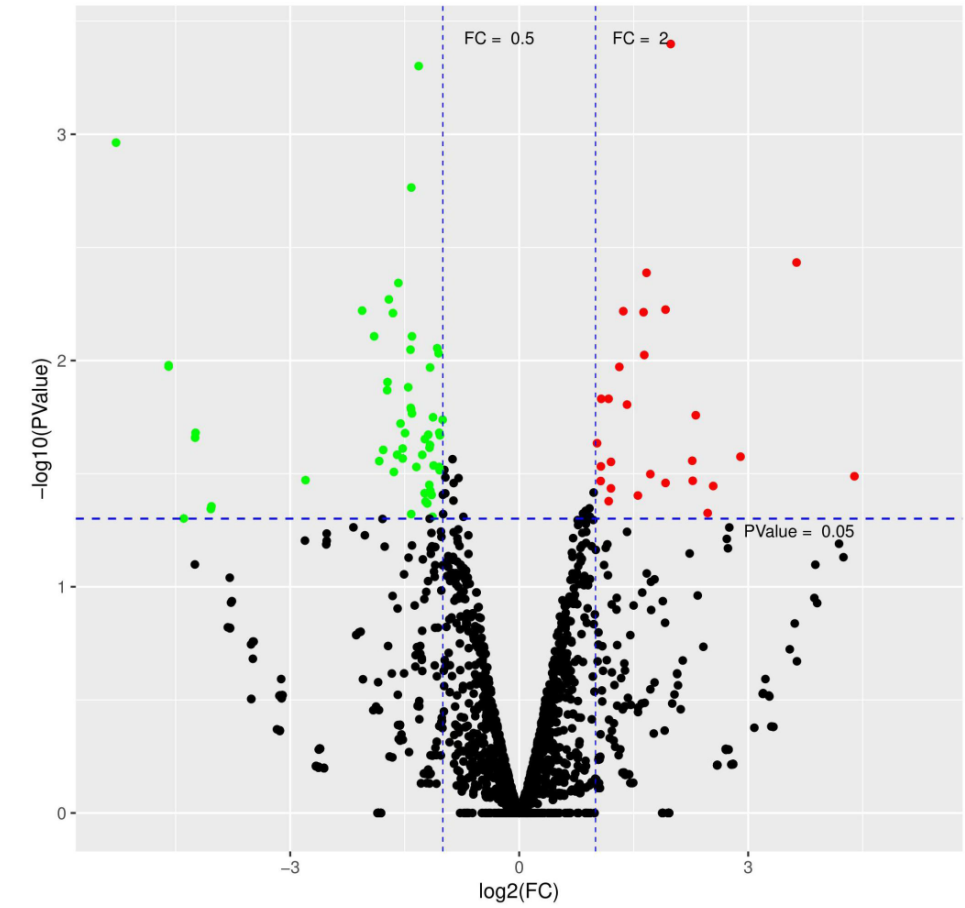

C

case1 VS control1, Pearson $R^{\wedge} 2=0.986$, Num. Up $=27$, Num. Down $=56$

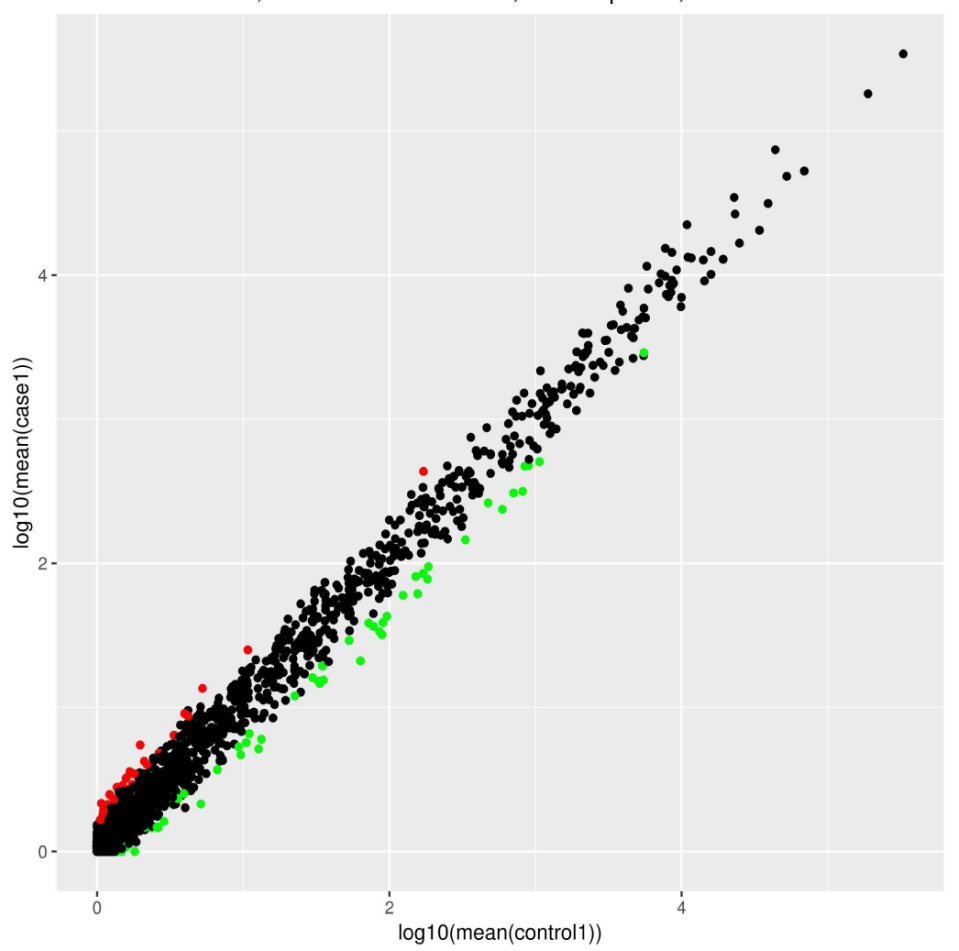



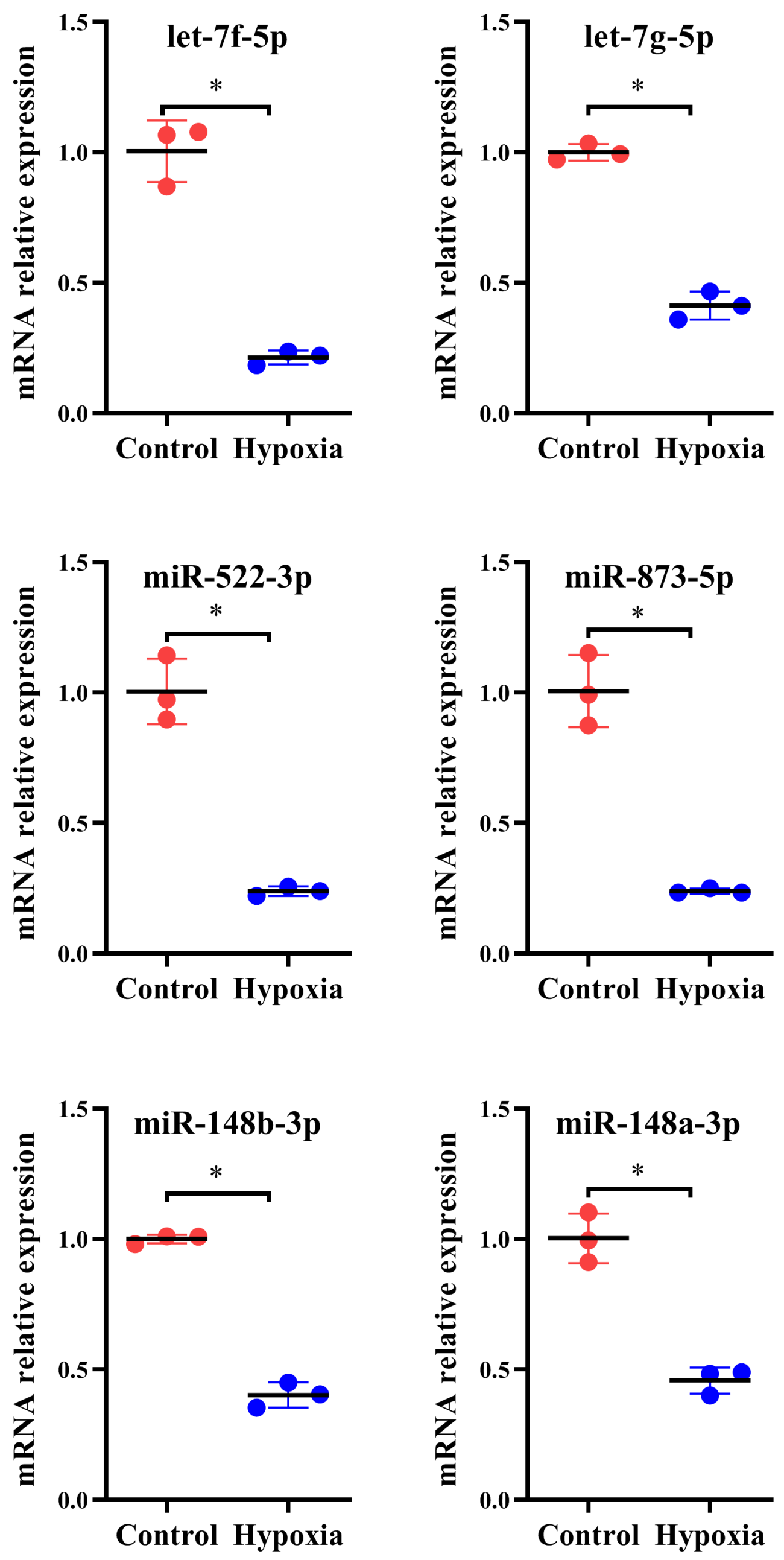

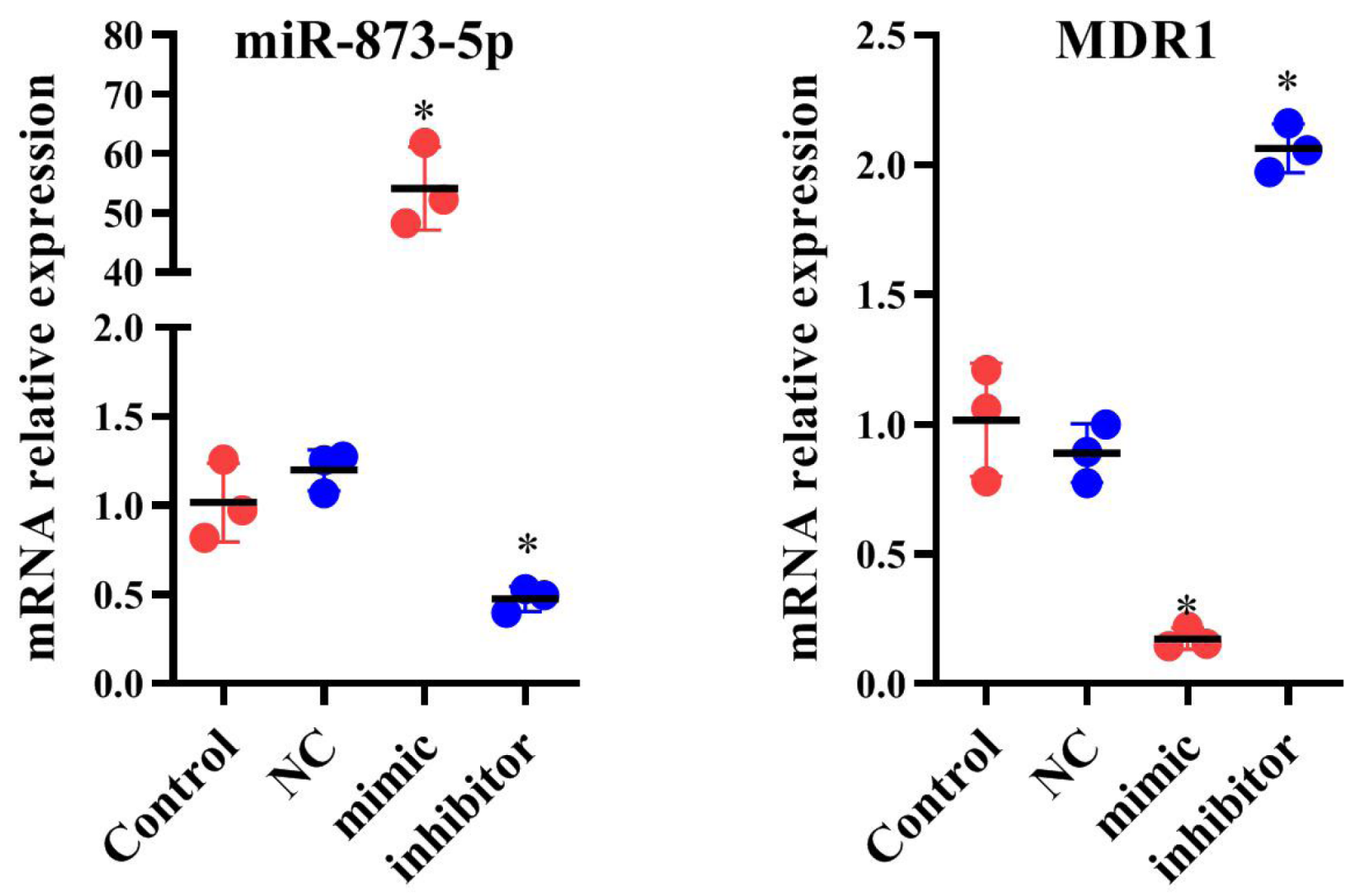

c
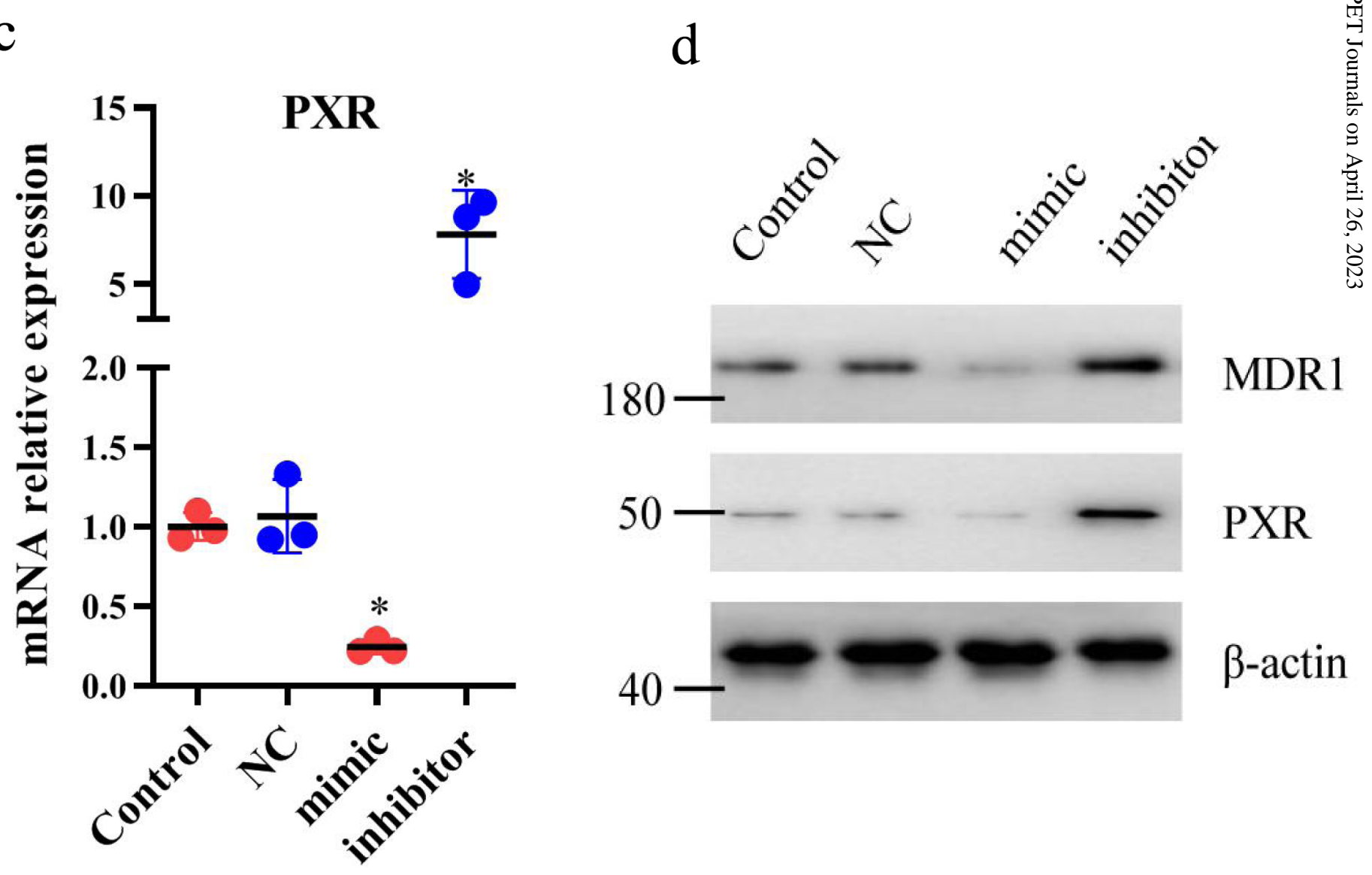

Figure 9 